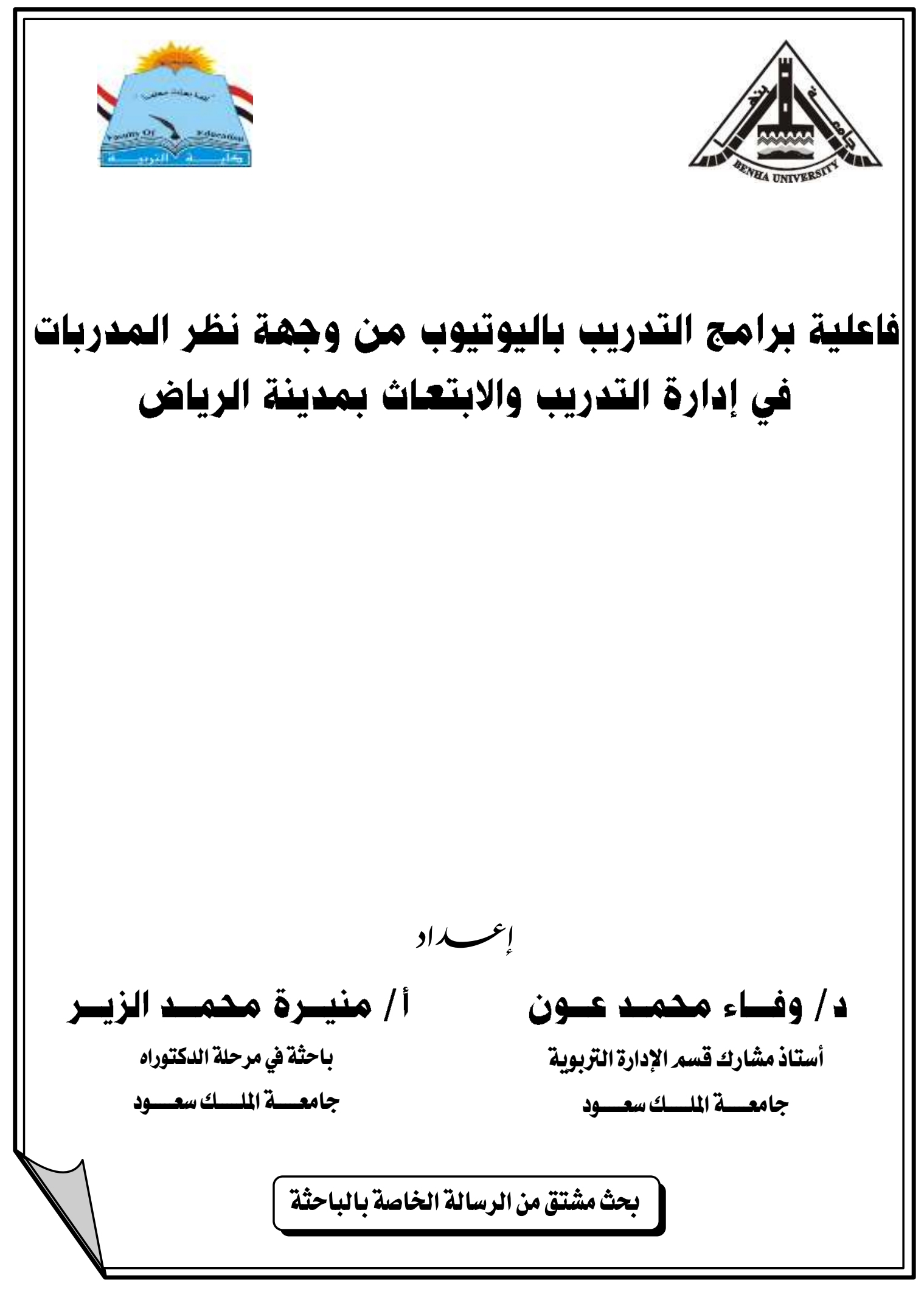




\title{
فاعلية برامج التدريب باليوتيوب من وجهة نظر المدربات في إدارة التدريب والابتعاث بمدينة الرياض
}

\author{
!兵
}

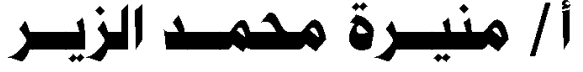

باحثة في مرحلة الدكتوراه

جامعة الملك سعود

\section{نو /}

أستاذ مشارك قسم الإدارة التربوية

جامعة الملك سعود

المستخلص

هدفت هذه الدراسة الى التعرف على فاعلية برامج التدريب باليوتيوب من وجهة نظر المدربات في إدارة التدريب والابتعاث بمدينة الرياض. وذلك من خلال معرفة الكفايات المطلوب توافرهـا لدى المدربـة لتقديم بـرامج تدريبيـة بـاليوتيوب، ومعـيير تصـميم ومستوى جودة بـرامج التدريب المقدمة باليوتيوب وكيفية تقييم برامج التدريب باليوتيوب. وقد تم استخدام المنهج الوصفي، وتكون مجتمـع الدراسـة من (Or) مدربـة في إدارة التدريب بالريـاض، وقد بلـغ عدد المستجيبات (ץ \&). استخدمت الباحثتان الاستبانة لجمـع المعلومات، ومـن أهم نتائج الدراسـة امتلاك المدربات للكفايات الخاصة بإنتاج فيديو اليوتيوب. ووجود فروق ذات دلالة إحصائية في استجابات أفراد العينة حول كفايات المدربة وتقييم برامج التدريب بمقاطع اليوتيوب لصـالح من لهم أكثر من (7) دورات. وأوصت الباحثتان بضرورة اعتراف وزارة التعليم بالتدريب الالكتروني، ومنح شهادات معترف بها، وإقامة دورات تدريبية مكثفة في التدريب عن بعد واستخدام اليوتيوب في التدريب.

\section{الكلمات المفتاحية:}

التدريب، التدربب التقني، التدريب الاكتروني، التدريب بمقاطع اليوتيوب. 


\section{Abstract}

This study aimed to identify the effectiveness of training in Youtube from the point of view of the trainers in the management of training and scholarships in Riyadh. And to identify the competencies required by the trainer to provide training programs YouTube, and the design standards and the quality of training programs YouTube and how to evaluate. And the use of descriptive approach, and the study community of (52) trained in the management of training in Riyadh, and the most important results of the study of the trainers possess the competencies of the production of video YouTube. And the existence of differences of statistical significance in the responses of members of the sample on the competencies of the trainer and evaluation of training programs sections YouTube for those who have more (6) courses.The two researchers recommended that the Ministry of Education should recognize electronic training, intensive courses for distance training and use of YouTube in training.

\section{Keywords:}

Training, technical training, e-training, YouTube training. 
يحتل التدربب مكانة مهمة بين أنشطة الموارد البشرية في أي منظمة لما لـه من دور كبير في تتمية مهارات العاملين ورفع قدراتهم الشخصية، وبالتالي المساهمة في تحسين الأداء ورفع الكفاءة وزيـادة الإنتاجية في العمل، وقد زاد الاهتمام من قبل المنظمات بالتدريب بشكل عام والأساليب التدريبية بشكل خاص في تعدد وتتوع أساليب التدريب وأصبح العديد من هذه الأسـاليب يرتبط وبشكل كبير بالتقنية الحديثة سواء في مجال الحاسب الآلي أو الاتصـالات الأمر الذي ساهم وبشكل كبير في رفع كفاءة البرامج التدربيية وزيادة فاعليتها. ويأتي التدريب عن بعد بديلاً مطوراً عن التدريب التقليدي ويمتاز التدريب عن بعد بكونه تدريب جماهيري يقوم على فلسفة تؤكد حق الأفراد في الوصول إلى الفرص التدرببية المتاحـة بمعنى أنـه تـدربب مفتوح لجميـع الفئـات، لا يتقيد بوقت أو فئسة مـن المتدربين ولا يقتصر على مستوى أو نوع معين من التدربب فهو يتوائم مـع حاجات الأفراد في مجتمعاتهم ويرقى بطموحاتهم. (كردي، · 1 • ب ) ولقد أحدثت التطورات التي شهدتها مجالات تقنية المعلوماتية والاتصالات نقلة نوعية أو ما يعرف بالتحولات العالمية التي أثرت في جميع العمليات التعليمية والتدربيية، حيث أدت هذه التحولات إلى ظهور آليات حديثة في طرق اكتسـاب المعارف والمهارات وفي وسـائل ونقلهـا وإسـتراتيجيات توليــها. وأصـبح مـن السـهولة بمكـان توظيـف تقنيـة الاتصـالات والمعلومـات وتطويعها للحد من هوة الفوارق الاجتماعيـة والثقافيـة , وتخطي قيود الزمـان والمكان وندرة الموارد البشرية، ووفقاً لهذه التحولات المعاصرة، فقد تعددت أسـاليب التدربب الإكتروني ومنها التدريب من خـلال بث مقاطع فيديو قصيرة ورفعها على تطبيق اليوتيوب والذي يعد أكبر مصدر للفيديو عبر الإنترنت في العالم حيث تجاوزت عدد المشاهدات اليومية لتلك المقاطع ملياري مشـاهدة في اليوم الواحد، وأكثر من مليار زيـارة كل شهر، كما يلعب اليوتيـوب دوراً رئيسـاً في تعزيـز عمليـة التـدربب والتتعلم، فهو مـورد غيـر محدود لتعلم. .(Guemide, Benachaib Bedri ,2014) يُعرف التدريب بأنه نشاط مخطط يهدف إلى إحداث تغييرات في المتدربين من ناحية معلومـاتهم ومعـارفهم ومهاراتهم وسلوكياتهم بما يجعلهم لائقين لأداء أعمالهح بكفايـة وإنتاجيـة

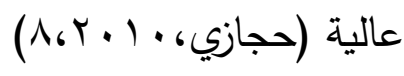


وتبرز أهمية التدريب في أن الفرد الدرّب هو من يستطيع انجاز أعماله بطريقة أفضل

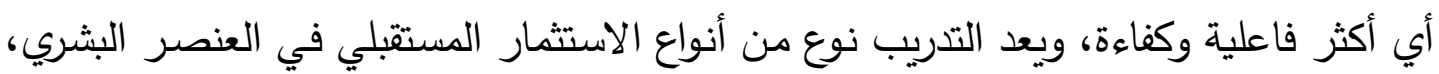

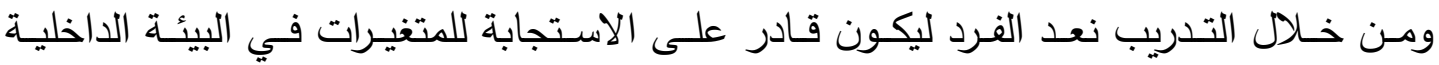
والخارجية، فلا يمكن الاستفادة من التقنية الحديثة دون تدريب العاملين عليها، ويساعد التدريب

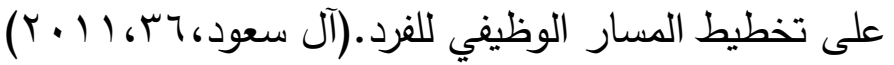

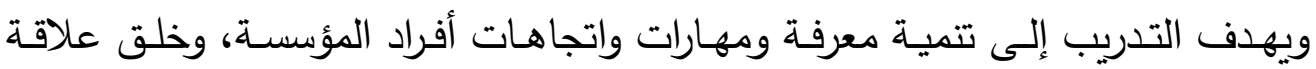

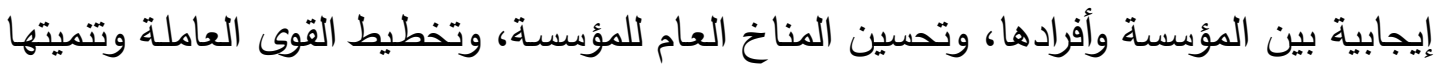

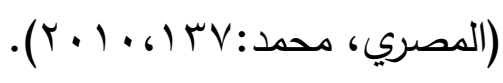

ومن الاتجاهات الحديثة للتدريب إنشاء مراكز للتدريب الإككتروني لنشر وتعزيز ثقافة

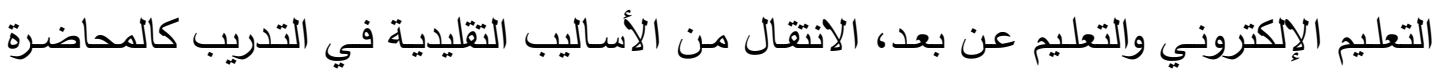
والمناقثـة والندوة والمؤتمر وغيرهـا إلى الأسـاليب الحديثة كسلة القرارات والمباريـات الإداريـة والتدريب عن بعد والمحاكاة(المهنا، وبـ ـ ().

يعرف (حسن، 9 . r) التدريب الإلكتروني عملية يتم من خلالاها تقديم البرامج التدريبية

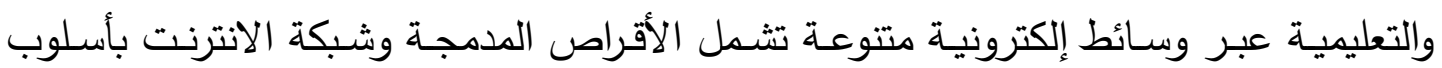
متزامن أو غير متزامن وباعتماد مبدأ التدرب الذاتي أو التدرب بمساعدة مدربه لتصني. وتخاطب مقاطع الفيديو جميع الحواس، وتساعد على إدرا ك الحقائق وفهمها، وذلك عن طريق تقديم المحتوى بشكل جذاب، وتختصر على المدرب الكثير من التفاصيل، وتزويد المتدرب إنى بخبرات حقيقية وتساعده على التعلم الذاتي.

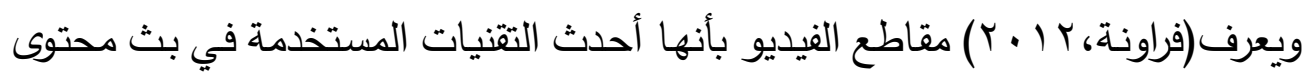

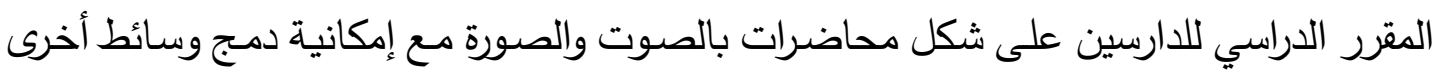
لتوفير فرص للتفاعل المتزامن من خلال شبكة الإنترنت.

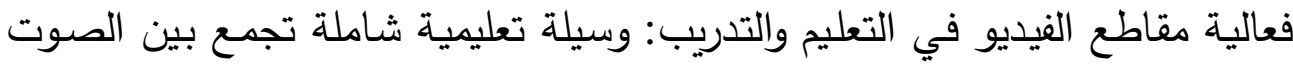
والصورة والحركة، وتتميز سهولة تسجيل مقاطع الفيديو وحفظ المواد المسجلة، والمشاركة

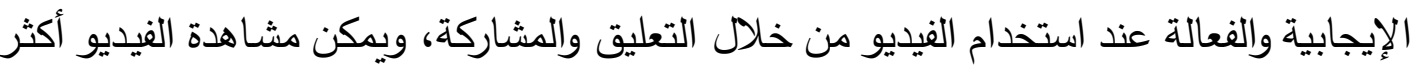

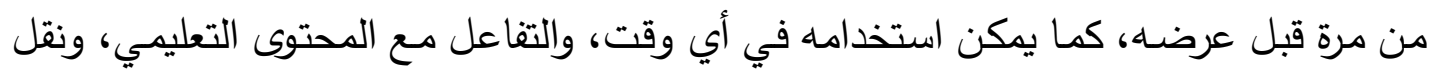

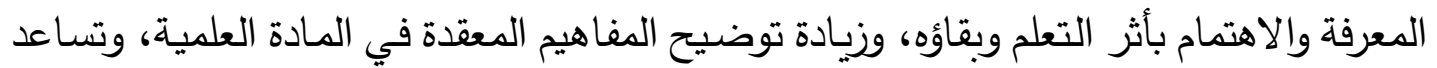


المتدرب على التعلم الذاتي مما يزيد من كفاءة العملية التدريبية، وتعزيز دافعية المتدرب للتعلم

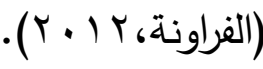

وأصبحت خدمات الإنترنت توفر للمدربين والمتدربين محتوى يمكن الاستفادة منه، ومن هذه الخدمات موقع مشاركة الفيديو مثل اليوتيوب الذي يعتمد على إضافة المستخدمين لمقطع

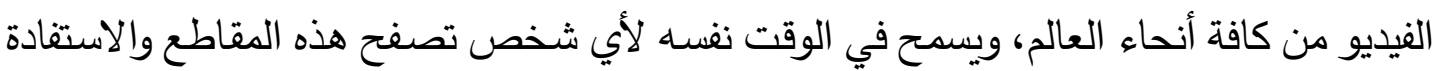

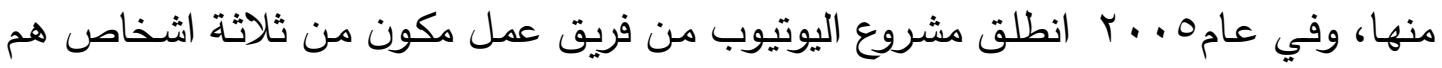
(تثاد هيرلي وستيف تشن وجاويد كريخ) نثأة الفكرة عندما كانوا في حفلة لأحد الاصدقاء وهنالك

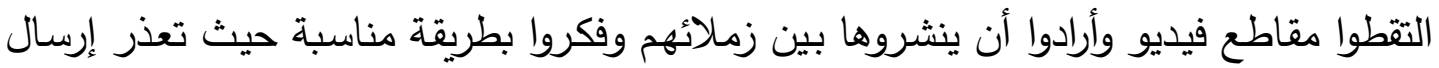

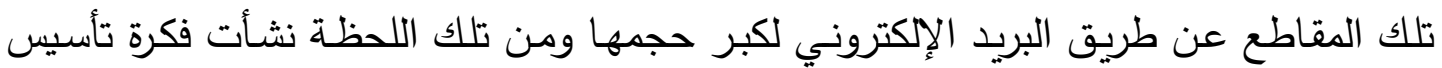
موقع لتبادل لقطات الفيديو على أن يكون الموقع سهل الاستخدام وسهل التحميل، وفي عام ونام

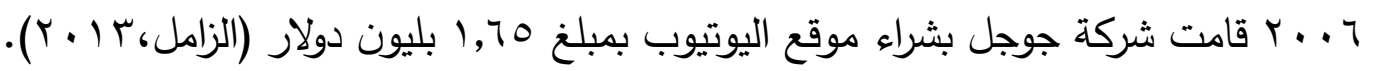

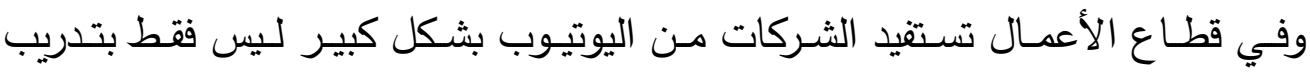

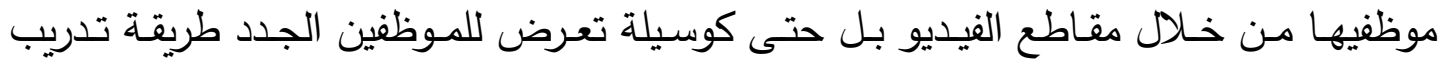

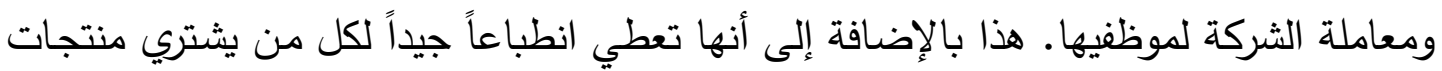

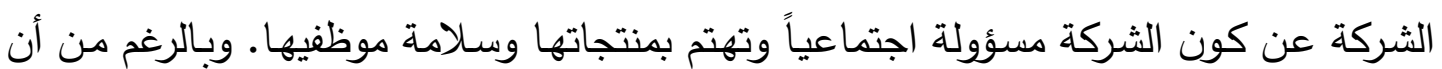

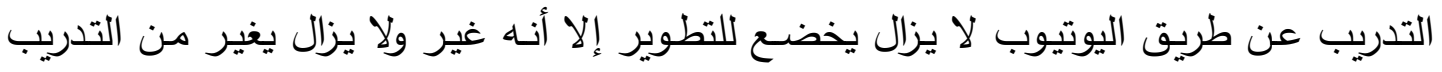

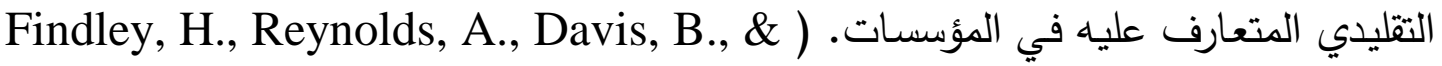

(Belcher, W. 2013

وحدد (فراونة، Y I Y أبرز الخصائص الرئيسة في موقع اليوتيوب ومنها إنتاج فيديو منخفض الكلفة، وإضافة عنوان رئيس يصف الفيديو، ويمكن إنشاء قنوات منفصلة لكل مستخدم،

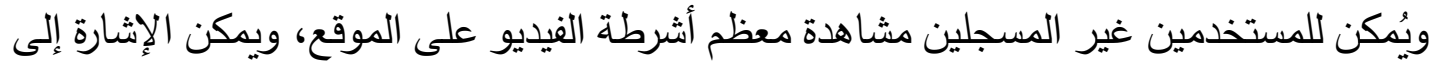
أن بعض محتويات الفيديو غير لائقة أو لا تتاسب القصّر ، ومعرفة المقاطع الجديدة من خلال الاشتراك والتسجيل بالبريد الإكتروني.

ويضيف (Findley, Henry, et al,2013) بعض الخصائص كالتحكم في إعداد

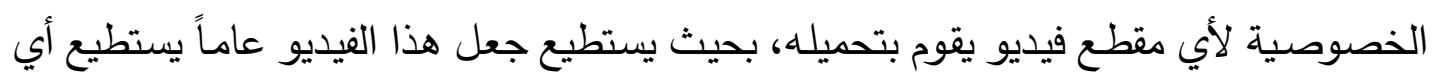
شخص مشاهدته على الإنترنت، أو غير مدرج يشاهده هو فقط، أو خاصاً لأشخاص معينين يملك هيك 
بريدهم الإلكتروني، وتصنيف الفيديو الذي حمّله إلى مجموعة من الفئات منها :التعليمية،

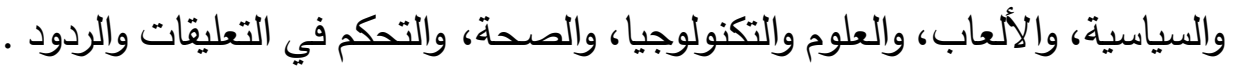

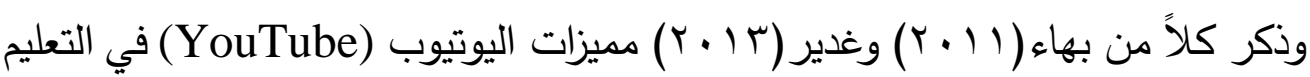

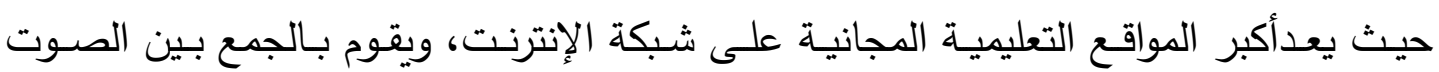
والصورة في العملية التعليمية، ويتيح للمتعلمين الوصول الى المعلومـة في أي وقت وزمانهان.

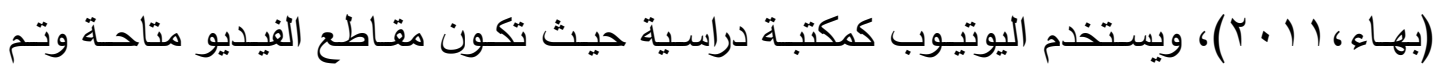

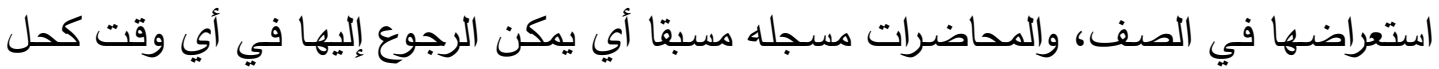

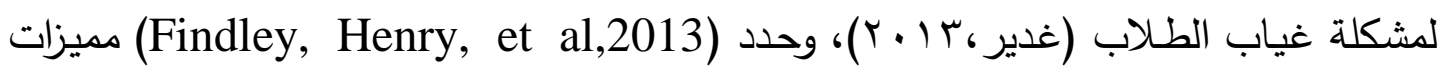
اليوتيوب والتي ساهت بشكل كبير في نجاحه حيث يعتبر من وسائل التدريب ذات فترة زمنية قصيرة وتكلفة مادية قليلة، ويمكن الاحتفاظ بمواد تدريبية متتاغمة مـع العروض التوضيحيةـ وسهولة الوصول إلى المواد التدريبية، وسهولة استخدام اليوتيوب وملاءمته للاستخدام في كافة الإئة

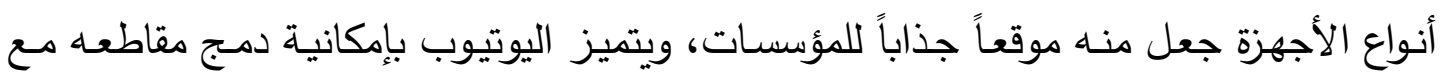

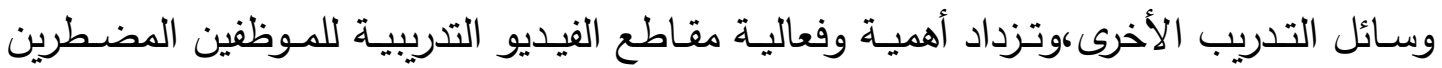
للسفر من أجل التدريب.

وذكر (فراونه، Y + r) مميزات أخرى لليوتيوب كالتثجع على الإبداع،و كونها توفر

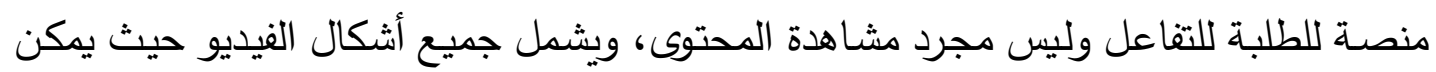
اعتباره موقعاً لنشر الفيديو حسب الطلب، أو لبث فيديو مباشرة، أو في عمل لقاء ات مباشرة ولثرة كفيديو تفاعلي بين أكثر من شخص في نفس الوقت، وسهولة إدارة مقاطع الفيديو والتعليقات عليها،

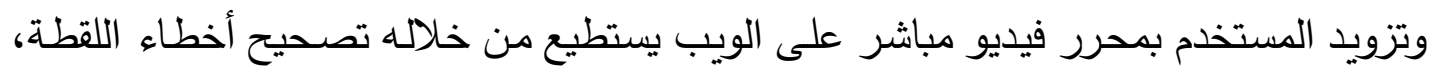

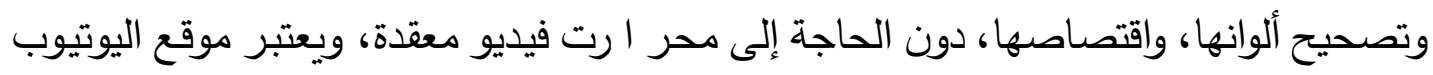
أكبر موقع فيديو من حيث عدد الزوار والمستخدمين.

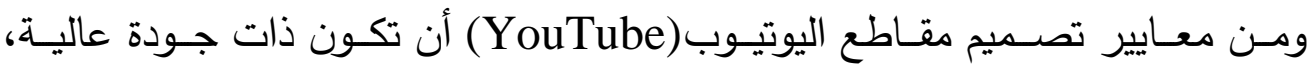

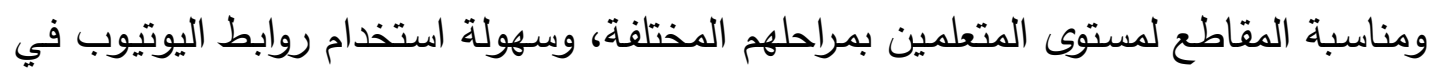

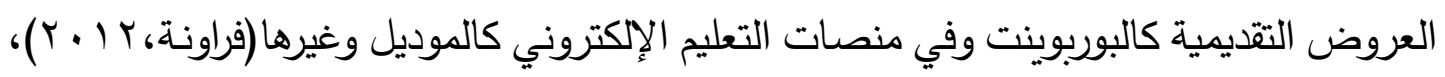

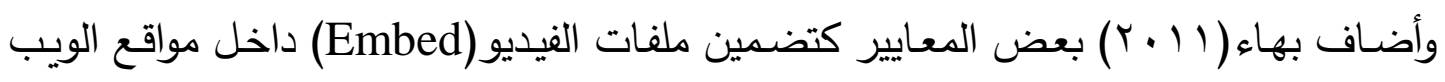

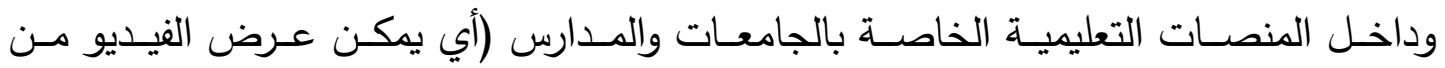


بouTube داخل المواقع والمنصـات الإكترونيـة بـدون الذهاب إلى موقـع YouTube)، والتعليق بتغذية راجعة Feedback على مقاطع الفيديو المنشورة وتتييمها بالإضـافة إلى حفظ مقاطع الفيديو.

\section{ومن أهم طرق تقييم مقاطع اليوتيوب التعليمية:}

1- استعراض كامل مقاطع الفيديو المراد استخدامها في التتريب والتأكد من سلامتها العلمية واللغوية.

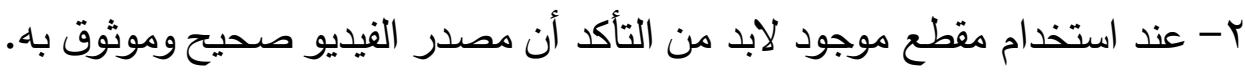
r- يمكن مشاركة بعض المتربين في تثييم مقاطع الفيديو ومناقثة مدى مناسبتها للمحتوى التدريبي.

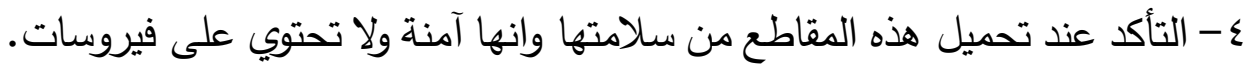
وتتم عملية التقييم بثلاث طرق وهي التقويم الذاتي ويتعلق بتقديرات آراء المستفيدين وفقاً لكعايير محددة، والتقويم الموضوعي ويتم من خلال جهاز حاسب بشكل آلي وفقاً لمعايير فنية ترتبط بجودة الصورة، وجودة البث، و التقويم المختلط والذي يصدم بحيث يتضمن كلا النوعين السابقين معاً.

ويعتبر اليوتيوب من أكثر أدوات التعلّم الإلكتروني شيوعاً وهو حائز على التصنيف

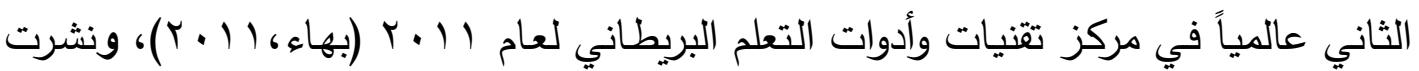
شركة اليوتيوب وفق آخر إحصائية بموقعها الإكتروني قائمة لأكثر من (600) قناة جامعية الئل

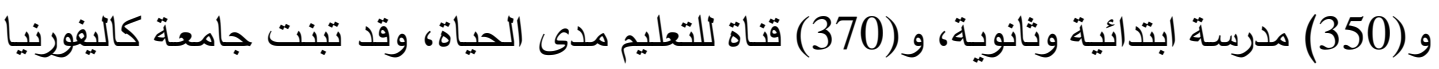
في بيركلي اليوتيوب كوسيلة تعليم، حيث بضغطة زر على صفحة بيركلي UCفي اليوتيوب

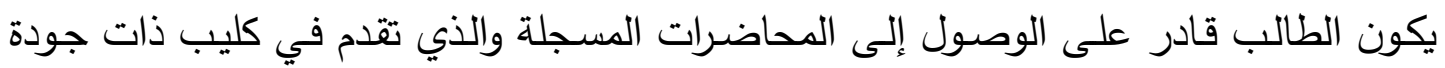

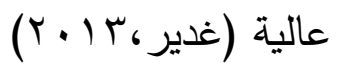

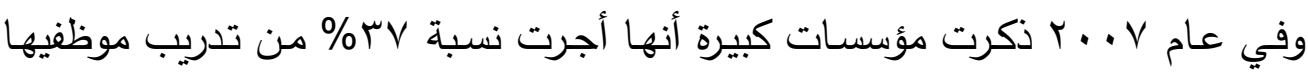

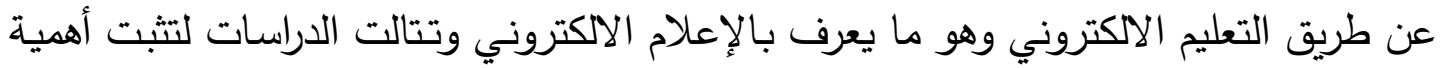
التركيز على تطوير مهارات الموظفين مها اضطر أصحاب العمل للبحث عن طرق تطوير غير مكلفة مثل طرق التدريب الالكترونية (Findley, Henry, et al,2013).

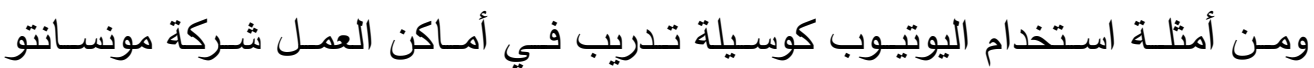

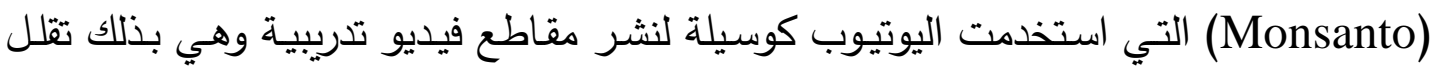

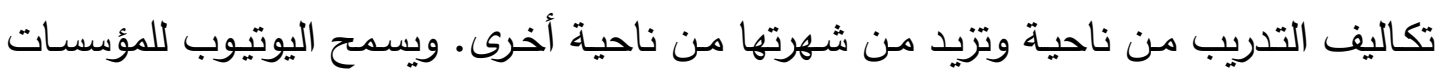


بخيارين: إما أن تتشر المؤسسة مقاطع الفيديو الخاصة بها على الموقع ويتمكن الموظفين من

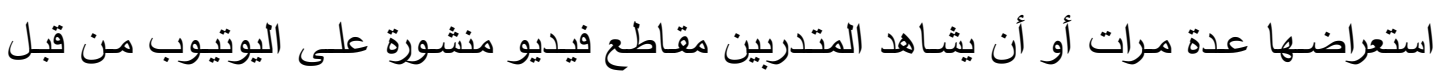

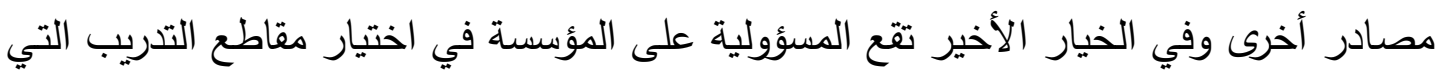
تتناسب مع احتياجات المتدربين. (Findley, Henry, et al,2013)، ومن أشكال التدريب التئي الأخرى التي يمكن البحث عنها في اليوتيوب هي تدريب المسوقين و تدريب مسؤولي الموارد

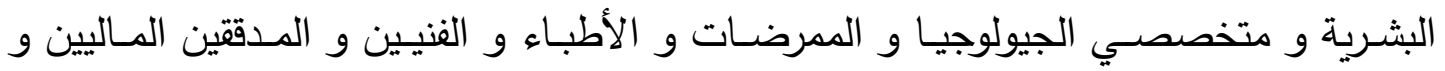

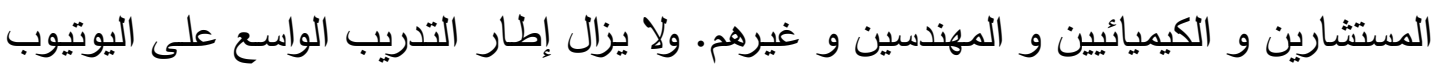
يتزايد في الاتساع وضم العديد من المهن.

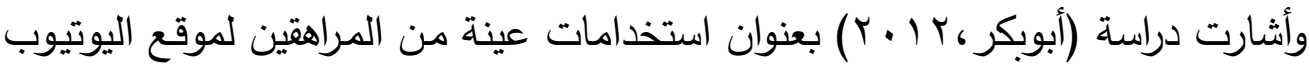

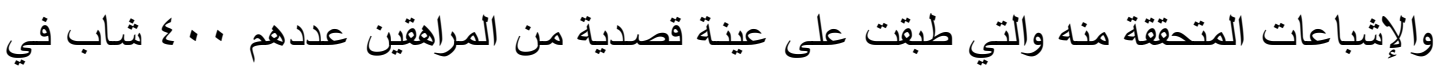

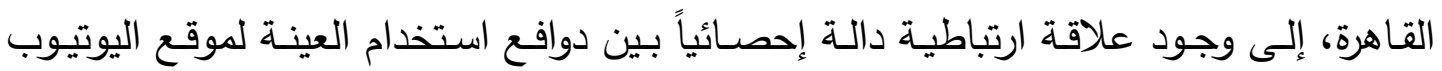
والإشباعات المتحققة لهم.

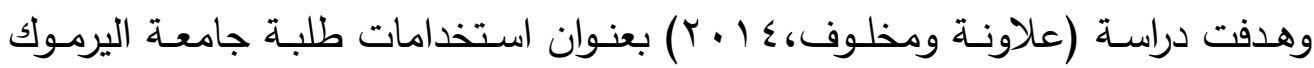
لليوتيوب والإثشباعات المتحققة منها، إلى التعرف على استخدامات طلبة جامعـة اليرموك

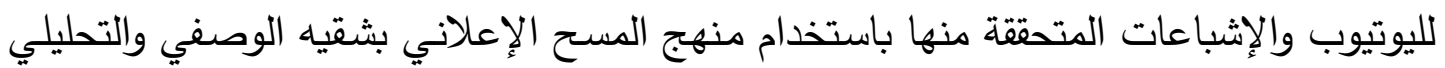

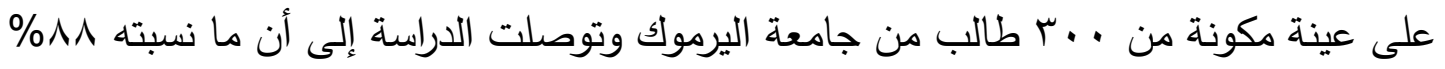

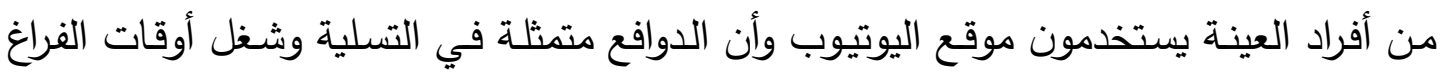
وزيادة المعرفة والاطلاع على الاحداث المحلية والدولية والحصول على مقاطع نادرة.

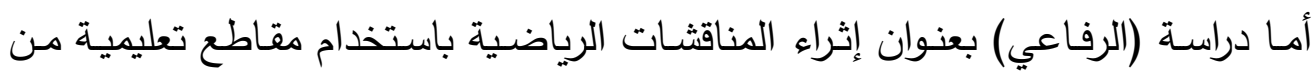

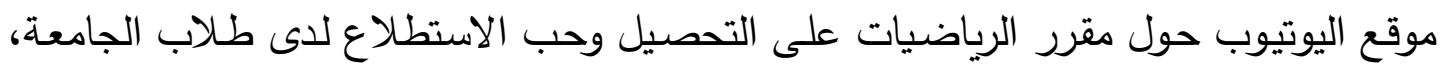

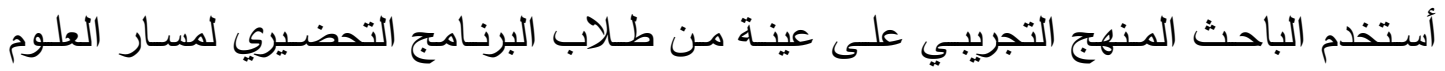

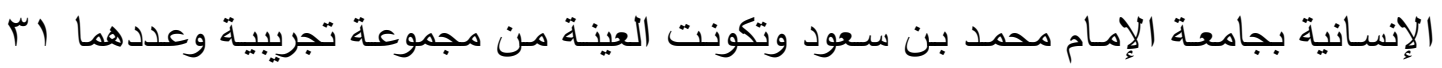
طالب ومجموعـة ضـابطة وعددها سب طالب واستخدم الباحث 7 اختبارات تحصيلية وقائمـة

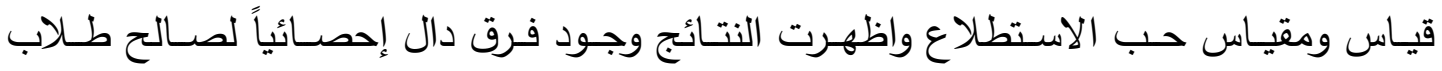
المجموعة التجريبية في الاختبار r و r بسبب مقاطع اليوتيوب في شرح المفاهيم الرياضية.

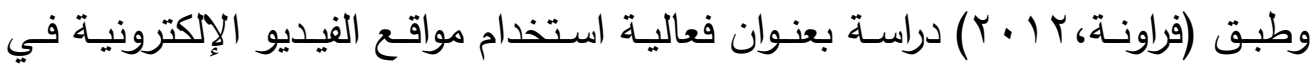
أكساب مهارات تصميم الصور الرقمية لاى طالبات كلية التربية في الجماعة الإسلامية بغزة درانية 
حيث استخدم المنهج التجريبي وعينة قصدية مكونة من ـ طالبة تم تقسيمها إلى مجموعتين تجريبية وضـابطة واستخدم الباحث عدة أدوات اختبار معرفي وبطاقة ملاحظـة وبطاقـة تقييم ملصـق تعليمي وتوصـلت الدراسـة إلى النتائج التاليـة :لا توجد فروق بـين متوســ درجـات المجموعتين في الاختبار المعرفي وتوجد فروق بين متوسط الدرجات في التطبيق لمهارات تصـيم الملصـقات ومهـارات تصـميم الصـور الرقميـة لصـالح المجموعـة التجربيـة، وتوصـلت الدراسة إلى ضرورة توظيف مواقع الفيديو الإلكترونية في التعليم الجامعي. أما دراسة (خلف الله، ع ـ ب ب) بعنوان فاعلية اختلاف أنماط التواصل (ثنائي - متعدد) عبر اليوتيوب والدافعية للتعلم (مرتفعة - منخفضة) في تقديم مقرر الوسائل التعليمية للدارسين بالتأهيل التربوي بجامعـة الأزهـر لتتميـة التحصيل والأداء والاتجاهـات، ذات المنهج التجريبي والمطبقة على عينـة مكونـه من ^^ ـ دارس واستخدم الباحث الاختبار التحصيلي وبطاقة ملاحظه كأداة لجمع المعلومات وتوصلت الدراسة إلى فاعلية البرنامج المقدم باليوتيوب في نتيجة التحصيل والأداء وفي الاتجاهات نحو التعلم باليوتيوب بغض النظر عن نمط التواصل ومستوى الدافعية.

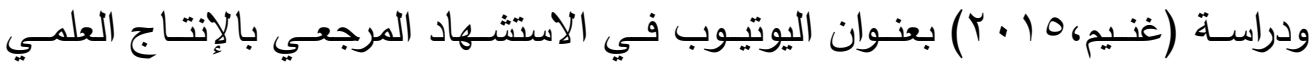
الأكـاديمي: دراسـة استكثــافية تحليليـة. طبقــت الباحثـة المـنهج الوصـفي التحليلـي والمـنهج الويبومتري وعينة طبقية لمقاطع اليوتيوب وزعت وفقا لحجم الفيديوهات في كل مجال موضوعي

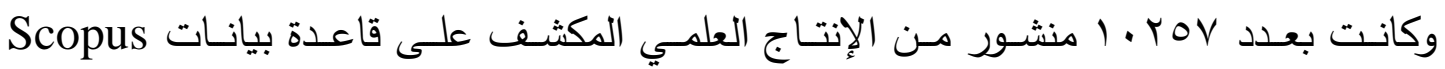
والمستشهد بفيديوهات اليوتيوب ما بين مقالات وأعمال مؤتمرات ومراجعات علمية استرجع منها

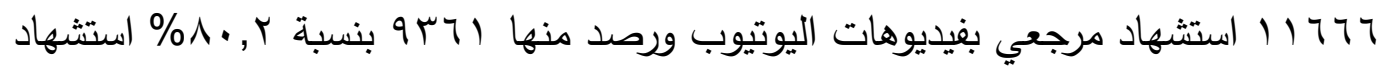
وتوصلت دراسـة (محمد، • 1 • ب) بعنوان الاستخدامات المهنية لمواقع مشـاركة الفيديو على شبكة الانترنت :يوتيوب نموذجاً، ذات المنهج الوصفي التحليلي والمطبقة على عينة من مقاطع الفيديو المنشورة بقنوات المؤسسات المهنية ذات الصلة بتخصص المكتبات على موقع اليوتيوب حيث قام الباحث بتحليل مضمون تلك المقاطع مستعمل أداة نموذج من الأسئلة، إلى أن قنوات المكتبات العامـة الأسبق والأكثر انتشـاراً وتفوقت قنوات المكتبات العامـة من حيث العدد على القنوات محل الدراسـة واحتلت القنوات المهنية بالولايات المتحدة الأمريكية المرتبـة

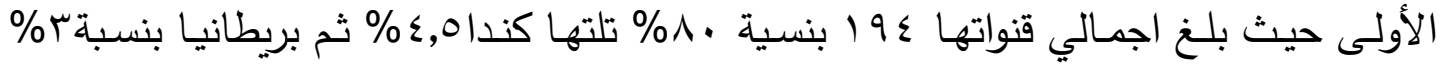
ورصد البحث قناتين لمكتبتين عربيتين هما مكتبة الإسكندرية بمصر ومكتبة المحمود بالثارقة، 


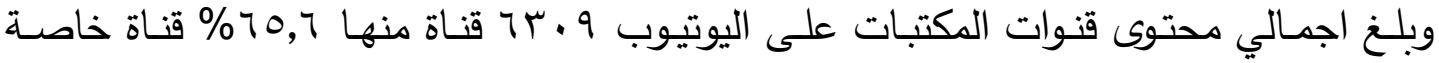

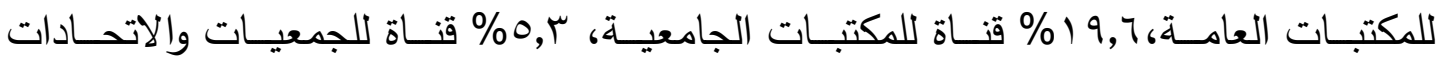
المهنية، ا,0\% بالمكتبات الوطنية،و ع, ؛ \% قناة لدكتبات الكليات.

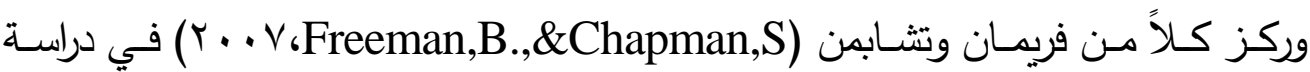
Is "YouTube" telling or silling you something?:Tabaco content on the بعنوان على دور اليوتيوب كوسيلة إعلانية ودعائية بديلة للإذاعة والتلفزيون الوطني والخاص

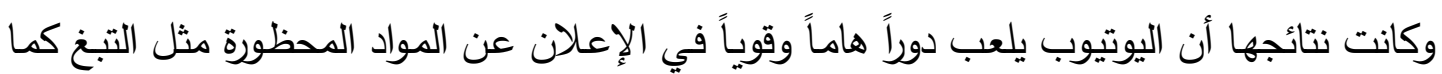
تدعو الدراسة منظمات مكافحة التبخ مراقبة اليوتيوب كوسيلة إعلانية والعمل على مواجهتها.

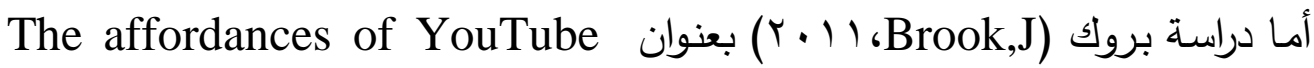
for language learning and teaching الإنجليزية كلغة أجنبية وبينت الدراسة أن اليوتيوب أداة تسهل تعلم اللغة وتعليمها وتتيح مجموعة من الأنشطة التي تركز على مشاركة الطالب كما ناقثه الدراسة مجموعة من القيود المحتملة لاستخدام اليوتيوب من قبل الطلبة مثل الخصوصية وظهور مواد غير لائقة أثناء الدرس. Using YouTube to enhance بعنوان student class preparation in an introductory Java course اليوتيوب لتعليم برمجة الجافا من خلال تجربة على مجموعة من طلاب أكاديمية الدفاع الجوي بالولايات المتحدة الأمريكية لقياس مدى إسهام هذه المقاطع في تعليم لغة الجافا وكانت نتائج

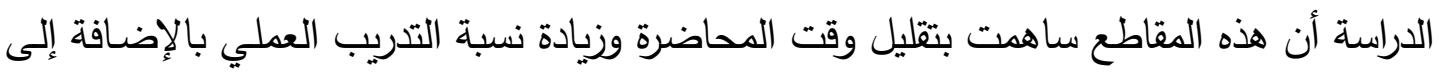
التأثير المباشر على المستوى التحصيلي للطلاب وزيادة درجات الاختبارات.

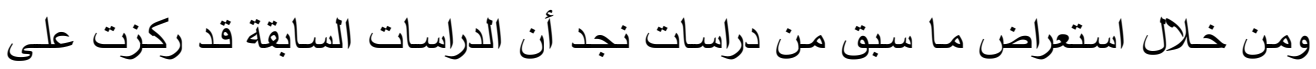
دراسة أنماط استخدام اليوتيوب وجمهور المستفيدين وتحليل محتوى المقاطع وتصنيفها ودور اليوتيوب في العملية التعليمية، إلا أن الدراسة الحالية تختلف عن الدراسات السابقة في تركيزها

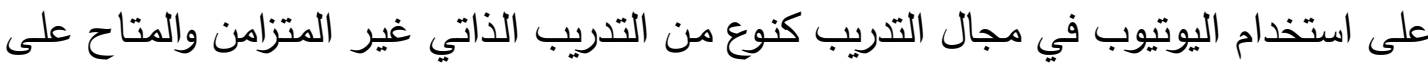
شبكة الانترنت وقد استفادت الدراسة الحالية من الدراسات السابقة في جوانب متعددة وبخاصة النتائج التي توصلت إليها هذه الدراسات. 
رغم التطور في الأسـاليب التدريبية إلا أن واقع الاستفادة منها لازال محدوداً، فالكثير من البرامج التدربية وخاصة في الوطن العربي لازال يعتمد وبشكل كبير على الأساليب التقليدية التي تركز على المحاضرات داخل القاعات التدربيية، وقد أكد الباحثين في مجال التدريب أن معظم الجهود التدريبية تصبح نتائجها محدودة الجدوى إذا ما اقتصر التدريب على الأساليب التقليدية (فايز ،0. • (1، • ع ()).

ومـع تفـاقم مشكلات التـدريب كعدم جاهزيـة القاعـات وشـح الأدوات التدرببيـة، ونقص

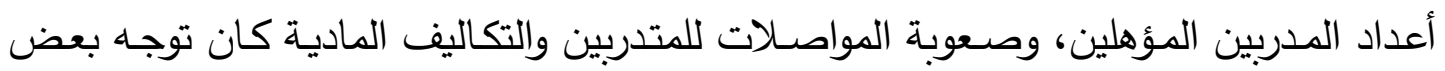
المجتمعات إلى التدريب الإكتروني كأحد الحلول لتلك المشكلات إلا أن التدريب الإلكتروني أيضاً يحتاج إلى خبراء في تطوير الويب وصيانة خوادم المواقع الإلكترونية وصسوبة الحصول على نسخ احتياطية لذا فإن أنسب الحلول الموازنة بين الفائدة التربوية والتكاليف المادية التي قد التد تكون العائق الأساسي في تنفيذ بعض البرامج التدربية والاستفادة منها. كما أوصت بعض الدراسات بضرورة استخدام مواقع الفيديو الإلكترونية (اليوتيوب) في التعليم، ومنها دراسة (Simo,et.al,2010)التي أكدت على ضرورة استخدام قنوات اليوتيوب من قبل المعلمين وذلك لدورها في تسهيل عمليـة تعلم الطلبة ودراسـة (Bride,et.sl,2009) التي أوصت بأهمية استخدام الاختبارات الذاتية المعتمدة على الفيديو كونها مفيدة تربوياً وتساعد طلبة المرحلة الجامعية في تحسين نقاط القوة والصعف عندهم (فراونة، I ( • ب). ولذلك يبقى موضوع التدريب باليوتيوب موضوعاً حيوياً وبحاجة إلى مزيد من البحث وهو ما سيتناوله هذا البحث بالتركيز والإجابة عن السؤال التالي: ما مدى فاعلية برامج التدريب باليوتيوب من وجهة نظر المدربات في إدارة التدريب والابتعاث بمدينة الرياض؟

\section{أهــــــاف البدــث: \\ يهدف هذا البحث إلى معرفة:}

فاعلية برامج التدريب باليوتيوب من وجهة نظر المدربات في إدارة التدريب والابتعاث بمدينة الرياض. هالكفايات المطلوب توافرها لدى المدربة للتدريب باليوتيوب. معايير تصميم وإدارة برامج التدريب باليوتيوب. مستوى جودة برامج التدريب باليوتيوب. 
كيفية تقييم برامج التدريب باليوتيوب.

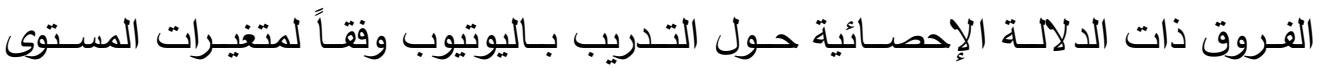
الأكاديمي والخبرة وعدد الدورات.

يجيب هذا البحث عن الأسئلة التالية:

ما مدى فاعلية برامج التدريب باليوتيوب من وجهة نظر المدربات في إدارة التدريب

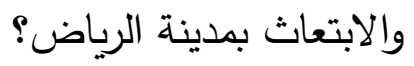

ها ما الكفايات المطلوب توافرها لدى المدربة لتقديم برامج تدريبية باليوتيوب؟

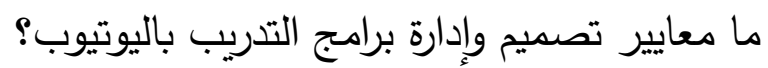

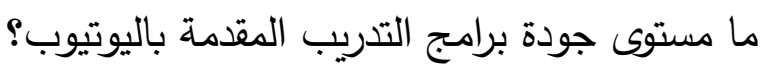

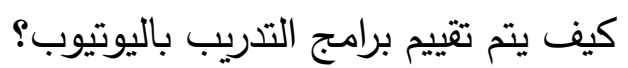

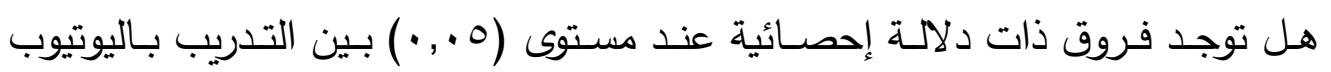

وعوامل أخرى مثل (المستوى الأكاديمي، الخبرة، عدد الدورات)؟

أهميـاسة البدـث

تتبع أهمية البحث باعتباره موضوع جديد لم يبحث من قبل في حدود علم الباحثتان

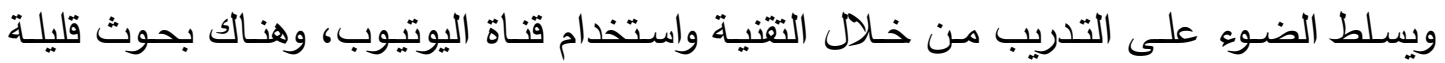

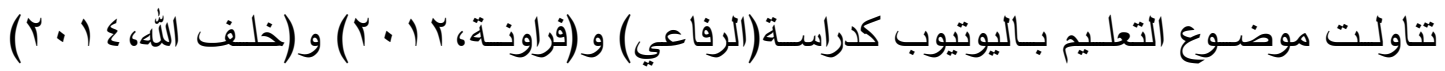

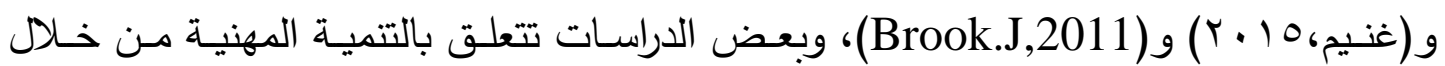

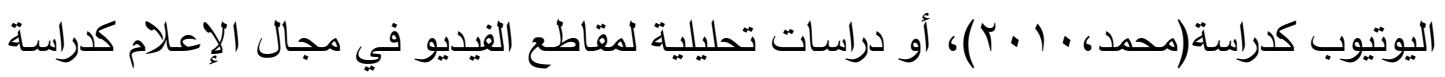

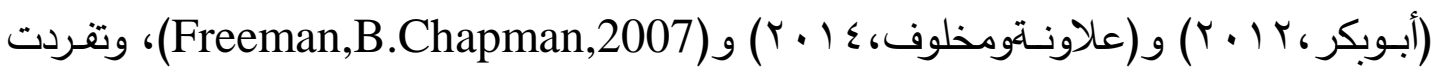

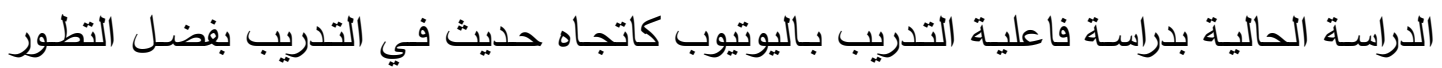

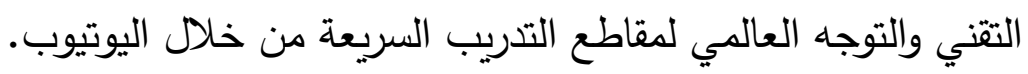

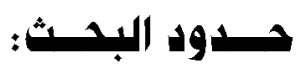

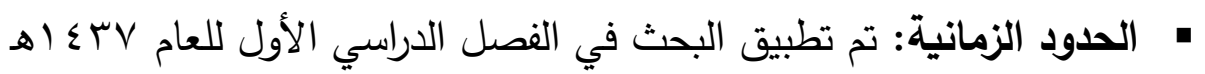

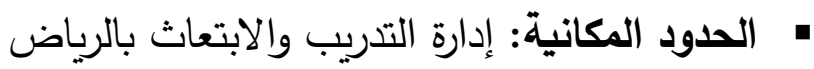

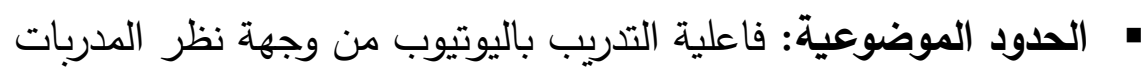
• الحدود البشرية: المدربات في إدارة التدريب بمدينة الرياض. 
التدريب في اللغة (اسم) جمعه : تدريبات ودرَّبَ يدرِبَ، تدريبًا، فهو مُدَرِب، والمفعول

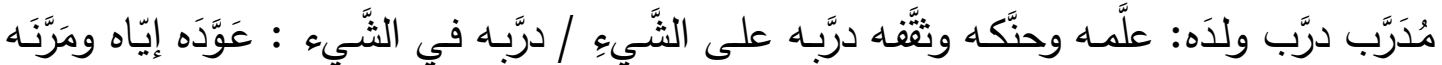

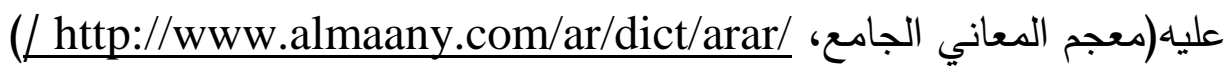

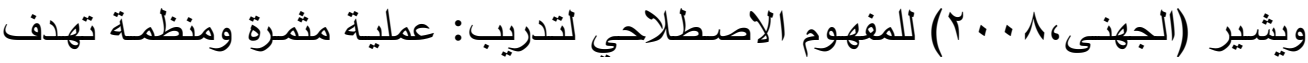

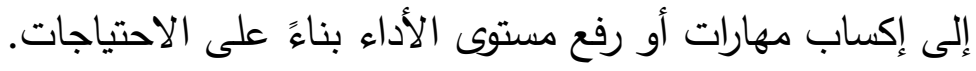

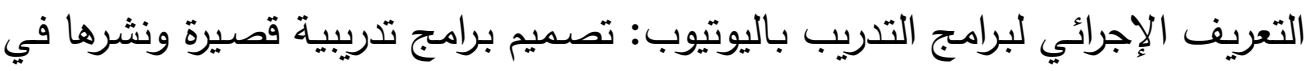

قناة يوتيوب خاصة بالمدرب ويتم بث مقاطع فيديو تدريبية من خلالها.

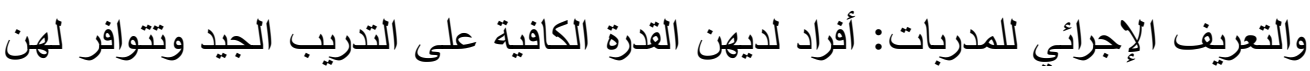

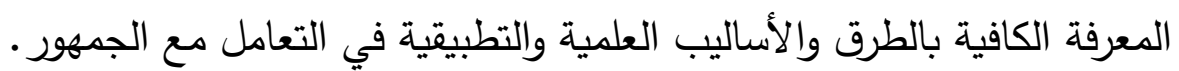

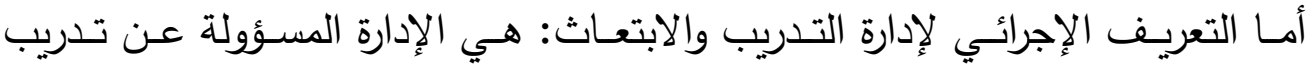

وابتعاث العاملين في وزارة التعليم
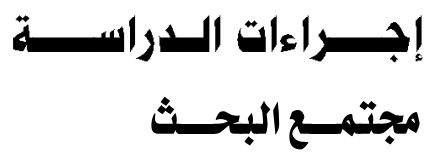

يتكون مجتمع البحث من جميع المدربات في إدارة التدريب والابتعاث بمينة الرياض حيث بلغ التخ

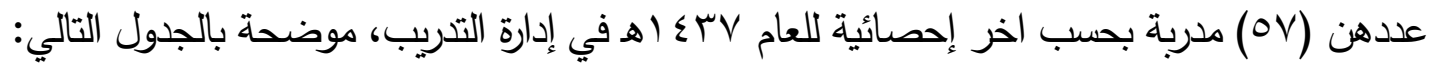
جلول (1) أعداد المدربات بإدارة التدريب والابتعاث بالرياض إضاض

\begin{tabular}{|c|c|}
\hline العــــدد & التخصـــــــ \\
\hline or & على رأس العمل \\
\hline r & ايفاد دكتوراه \\
\hline 1 & إجازة دراسية \\
\hline 1 & ايفاد ماجستير \\
\hline 1 & معارة لشركة تطوير \\
\hline or & المجموع \\
\hline
\end{tabular}

\section{عينـــة البحــث}

استخدم في هذا البحث العينة العشوائية حيث تم توزيع (ro (ب) استبانة على الدربات في

إدارة التدريب بالرياض، وقد بلغ عدد المستجيات (بع) في حين تم استبعاد عدد (• () استبانة

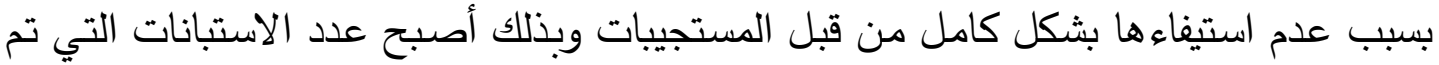
استخدامها في عملية التحليل (r \&) استبانة. 


\section{منهج البحث وأدواته}

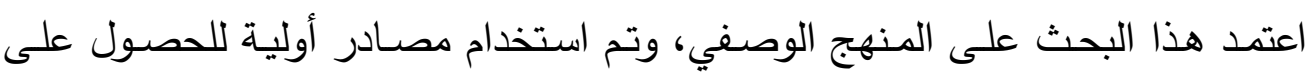
المعلومات كالاستبانة وذلك تمشياً مع متطلبات البحث الذي الذي يعتمد على دراسة الواتئ الواقع.

\section{الأساليب الإحصائية المستخدمة ؛}

1 - معامل الفا كرو نباخ لحساب ثبات الأداة.

r- بعامل ارتباط بيرسون لتحديد مدى الاتساق الداخلي لأداة الدراسة.

r- التكرارات والنسبة المئوية لوصف أفراد الدراسة.

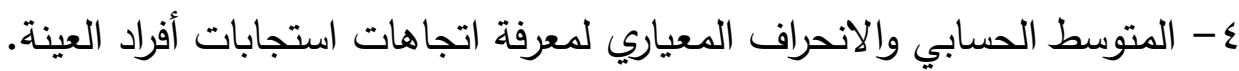

0- اختبار تاء (T) لمعرفة الفروق الإحصائية.

7- اختبار تحليل التباين لمعرفة الفروق الإحصائية.

- اختبار شيفيه (Schefft) لمعرفة مصدر الفروق الإحصائية.

طريقة حساب المقياس (الخماسي) ؛

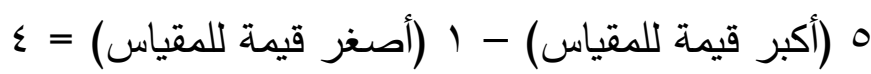

الجدول (ץ) طريقة حساب المقياس الخماسي الجياس

\begin{tabular}{|c|c|}
\hline درجة المواقتة & المتوسط \\
\hline موافق بشدة & $0-\xi, Y 1$ \\
\hline موافق & $\{, r \cdot-r, \xi)$ \\
\hline محايد & $r,\{\bullet-r, \eta$ \\
\hline غير موافق & $r, 7 \cdot-1, \lambda 1$ \\
\hline غير مواقق بشدة & $1, \Lambda \cdot-1$ \\
\hline
\end{tabular}

$$
\begin{aligned}
& \cdot, \wedge \cdot=0 / \varepsilon \\
& 1, \Lambda \cdot=1+\cdot, \Lambda \text {. } \\
& r, \uparrow \cdot=\cdot, \wedge \cdot+1, \Lambda .
\end{aligned}
$$

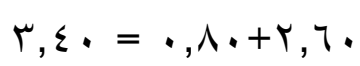

$$
\begin{aligned}
& \varepsilon, r_{\cdot}=\cdot, \Lambda_{\bullet}+r, \varepsilon \cdot \\
& 0=\cdot, \Lambda \cdot+\varepsilon, Y \text {. }
\end{aligned}
$$

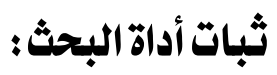

تم حساب ثبات الأداة باستخدام معادلة ألفا كرو نباخ ويوضـح الجدول رقم (1) قيمة معامل الثبات لكل جزء من أجزاء الاستبانة. 
الجدول (r) قيم معاملات الثبات لكل محور من محاور الاستبانة

\begin{tabular}{|c|c|}
\hline 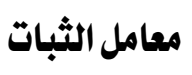 & 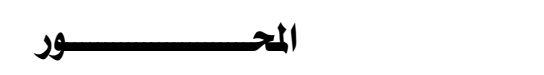 \\
\hline$\cdot, \wedge \leqslant 7$ & الكفايات الخاصة بالمدربة \\
\hline$\cdot, 9 \cdot 4$ & معايير تصميه مقاطع اليوتيوب \\
\hline$\cdot, \mathrm{rv}$. & جودة برامج التدريب بمقاطع اليوتيوب \\
\hline$\cdot, \Lambda \cdot r$ & تقييه برامج التدريب بمقاطع اليوتيوب \\
\hline$\cdot, \wedge 9 \gamma$ & كامل الاستبانة \\
\hline
\end{tabular}

ويتضـح مـن الجدول رقـم (r) أن قيم معـاملات الثبـات مرتفعـة ممــا يـدل على أن

الاستبيان يتمتع بدرجة عالية من الثبات.

صدق الاتساق الداخلي:

للتأكد من تماسك العبارات بالدرجة الكلية للمحور الذي تتنمي إليه نقوم بقياس صدق الاتساق الداخلي للأداة من خلال بيانات استجابات أفراد الدراسة بحساب معاملات الارتباط بين كل عبارة من عبارات المحور والدرجة الكلية للمحور الذي تنتمي إليه. الجدول (§) معاملات الارتباط لكل عبارة من عبارات المحوربالدرجة الكلية للمحور الذي تنتمي إليه

\begin{tabular}{|c|c|c|c|c|}
\hline \multicolumn{4}{|c|}{ معامــــــــل الارتبــــــــــــاط } & \multirow[b]{2}{*}{ مر } \\
\hline تقييم برامج التدريب & بودة برامج التدريب & مقايسر تصهييه & الكفايات الخاصة & \\
\hline$* * \bullet, 79$ & $* * \bullet, \wedge 01$ & $* * \bullet, \vee \vee \vee$ & $* * \bullet, \vee \neg 々$ & 1 \\
\hline$* * \bullet, \vee Y q$ & $* * \bullet, \wedge \wedge \Sigma$ & $* * \bullet, 119$ & $* *$, Aro & $r$ \\
\hline$* *, \mathbb{Z}\{\Lambda$ & $* *, Y \leq Y$ & $* * \bullet, 9 \leq Y$ & $* *$, Arr & $r$ \\
\hline ו I & & $* * \bullet, \wedge\rceil$. & $* * \bullet, \wedge \leqslant 1$ & $\xi$ \\
\hline \multirow[t]{4}{*}{$* *$, oor } & & $* * \bullet, \wedge r \mid$ & $* * \bullet, Y-1$ & 0 \\
\hline & & $* * \bullet, V Y Y$ & $* * \bullet, \operatorname{Trr}$ & 9 \\
\hline & & & $* * *, r \wedge l$ & $v$ \\
\hline & & & $* *,\{V Y$ & $\Lambda$ \\
\hline
\end{tabular}


يتضـح من الجدول رقم (ع) أن جميع معاملات الارتباط دالة إحصـائياً عند مستوى ( ( . • )، مما يثير إلى الاتساق الداخلي بين فقرات المحور والدرجة الكلية للمحور •

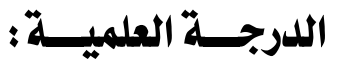

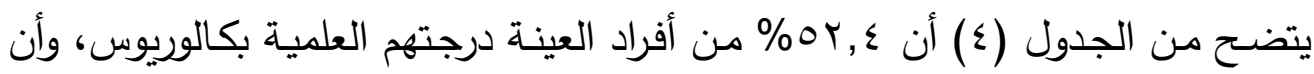
\% \& V,T يحملن مؤهل اعلى من البكالوريوس وهذا دليل على حرص الإدارة اثناء اختيار مرشحاتها. جلول (0) توزيع أفراد عينة الدراسة حسب الدرجة العلمية

\begin{tabular}{|c|c|c|}
\hline النسبة (\%) & التكرار & اللدرجة العلمية \\
\hline or, & rr & بكالوريوس \\
\hline$\leqslant \vee, \eta$ & r. & ماجستير \\
\hline 10. & $\xi r$ & المجموع \\
\hline
\end{tabular}

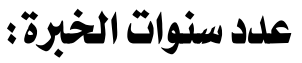

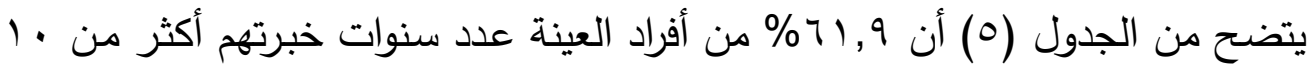

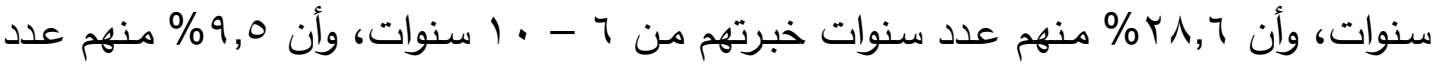
سنوات خبرتهم من 1 - 0 سنوات. أي ان أكثر منسوبات الإدارة من أصحاب الخبرة الطويلة. جدول ( ) توزيع أفراد عينة الدراسة حسب علد سنوات الخبرة

\begin{tabular}{|c|c|c|}
\hline النسبـــــة (\%) & التكـــــرار & عـــــد سنـــــوات الخـــــبرة \\
\hline 9,0 & $\xi$ & 1-0 سنوات \\
\hline YA, $\uparrow$ & ir & 7- - اسنوات \\
\hline 71,9 & rq & أكثر من · اسنوات \\
\hline $1 \cdots$ & $\xi r$ & المجموع \\
\hline
\end{tabular}

علد الدورات في مجال التلدريب:

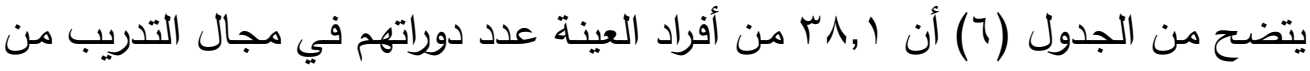

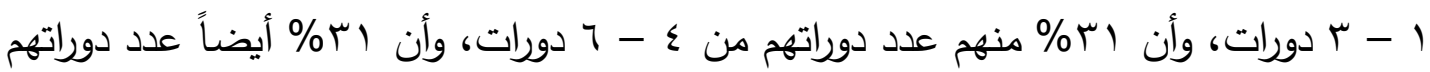
أكثر من 7 دورات. وحسب علم الباحثين بان إدارة التدريب تشترط قيام المدربـة بالتدريب لمدة • 0 ساعة تدربية قبل ترشيحها للعمل لكن لا يوجد لديها تخصيص للتدريب الاككتروني بالرغم من ظهور بدايات لهذا التوجه مؤخراً. 
جدول (V) توزيع أفراد عينة الدراسة حسب علد الدورات في مجال التدريب

\begin{tabular}{|c|c|c|}
\hline النسبة (٪) & التكرار & عدد اللدورات \\
\hline$r \wedge, 1$ & 17 & ا - بدورات \\
\hline r & ir & צ- צ دورات \\
\hline rl & ir & أكثر من ج دورات \\
\hline 1.. & sr & المجموع \\
\hline
\end{tabular}

\section{هل للديك قناة يوتيوب خاصة:}

يتضـح من الجدول (V) أن r,r^\% من أفراد العينـة ليس لديهم قناة يوتيوب خاصـة،

وأن V, > 1 \% منهم لديهم قناة يوتيوب خاصة يعزى ذلك من وجهة نظر الباحثتين لعدم اعتراف وزارة التعليم بالتدريب الالكتروني وبالتالي عدم إحساس المدربات بأهمية تعلم هذا النوع مـن التدريب وامتلاك قناة خاصة. جلدول (^) توزيع أفراد عينة الدراسة حسب وجود قناة يوتيوب خاصة

\begin{tabular}{|c|c|c|}
\hline النسبة (\%) & التكرار & الإجابة \\
\hline $17, v$ & $\checkmark$ & نعه \\
\hline$\Delta r, r$ & ro & y \\
\hline $1 .$. & $\varepsilon r$ & المجموع \\
\hline
\end{tabular}

هل تصتنفدمين القناة في التدريب:

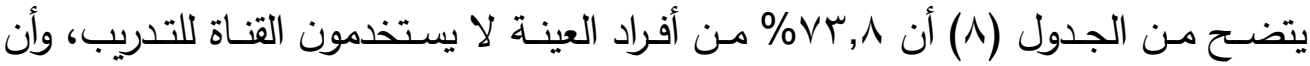

9 ( \% منهم يستخدمون القناة للتدريب. وهذا ناتج عن عدم وجود قنوات يوتيوب خاصة بالمدربة. جلول (9) توزيع أفراد عينة الدراسة حسب استخلاه القناة في التدريب

\begin{tabular}{|c|c|c|}
\hline النسبة (٪) & التكرار & الإجابة \\
\hline 19 & $\wedge$ & نعه \\
\hline$V_{r, \Lambda}$ & r & ע \\
\hline$v, r$ & $r$ & له يجيبوا \\
\hline $1 .$. & $\varepsilon r$ & المجموع \\
\hline
\end{tabular}




\section{عدد مقاطع الفيديو في القناة:}

يتضح من الجدول (9) أن 9 (1\% من أفراد العينة لديهم من 1 - r مقاطع في القناة،

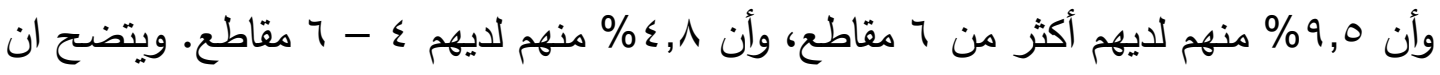
من لديه قناة خاصة يملك مهاره كافيه للإنتاج.

جلدول (•1) توزيع أفراد عينة الدراسة حسب علد مقاطع الفيديو في القناة

\begin{tabular}{|c|c|c|}
\hline النسبة (\%) & التكرار & الاجابة \\
\hline 19 & $\wedge$ & 1-r مقاطع \\
\hline$\xi, \wedge$ & 1 & צ- - مقاطع \\
\hline 9,0 & $\xi$ & أكثر من 7 مقاطع \\
\hline $77, Y$ & $r \wedge$ & لد يجيبوا \\
\hline $1 .$. & $\varepsilon r$ & المجموع \\
\hline
\end{tabular}

أولاً: الكفايات الخاصة بالمدربة

جدول (11) يبيز رأي أفراد العينة حول الكفايات الخاصة بالمدربة

\begin{tabular}{|c|c|c|c|c|c|c|c|c|c|c|}
\hline \multirow[b]{2}{*}{ 琈: } & \multirow[b]{2}{*}{ 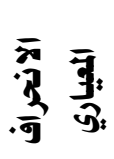 } & \multirow[b]{2}{*}{$\bar{d}$} & \multicolumn{5}{|c|}{ درجة المواقتة } & \multirow{2}{*}{\multicolumn{2}{|c|}{ العبــــــــارة }} & \\
\hline & & & غير موافق & موافير & محايل & مواقق & بشدة & & & هـ \\
\hline \multirow{2}{*}{$r$} & \multirow{2}{*}{ •, TVr } & \multirow{2}{*}{$\xi, r q$} & - & 1 & $r$ & rr & 17 & ك & \multirow{2}{*}{ للدي مهارة التعامل مع الحالئ } & \multirow[b]{2}{*}{1} \\
\hline & & & - & r,§ & $\xi, \Lambda$ & $\Delta \xi, \Lambda$ & $r \wedge, 1$ & $\%$ & & \\
\hline \multirow{2}{*}{$r$} & \multirow{2}{*}{$1,1 \%$} & \multirow{2}{*}{$r, r$} & 1 & ir & 11 & 1. & $v$ & 5 & \multirow{2}{*}{ للدي مهارة تصميثر الحقائب } & \\
\hline & & & $r, \xi$ & ri & $r q, r$ & $r r, \Lambda$ & $17, v$ & $\%$ & & \\
\hline \multirow{2}{*}{7} & \multirow{2}{*}{$1, \cdot \xi$} & \multirow{2}{*}{$r, A l$} & $r$ & $r$ & 9 & 14 & 11 & ك & \multirow{2}{*}{ شتلك مهارات التعامل مع } & \multirow{2}{*}{$r$} \\
\hline & & & $\xi, \Lambda$ & $\{, \Lambda$ & $M, \xi$ & $\{r, q$ & $r q, r$ & $\%$ & & \\
\hline \multirow{2}{*}{$\wedge$} & \multirow{2}{*}{$1, r$} & \multirow{2}{*}{$r, \cdot v$} & $r$ & it & 11 & $\Lambda$ & $r$ & ك & \multirow{2}{*}{ للفات القدرة على التعامل مع (المونتاج) } & \multirow[b]{2}{*}{ | } \\
\hline & & & $\mathrm{v}, \mathrm{l}$ & rI & $r q, r$ & 19 & $17, v$ & $\%$ & & \\
\hline \multirow{2}{*}{$r$} & \multirow{2}{*}{, वrq } & \multirow{2}{*}{$\varepsilon, Y q$} & 1 & $r$ & $r$ & iv & $r$. & ك & \multirow{2}{*}{ أستطيع شرح المفاهيم المققدة } & \multirow{2}{*}{0} \\
\hline & & & $r, \xi$ & $\mathfrak{\xi , \Lambda}$ & $\xi, \Lambda$ & $\{\cdot, 0$ & 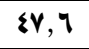 & $\%$ & & \\
\hline \multirow[b]{2}{*}{0} & \multirow[b]{2}{*}{ - } & \multirow[b]{2}{*}{$r, 90$} & - & $r$ & 11 & it & 10 & كt & \multirow{2}{*}{ 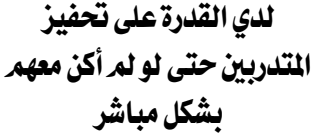 } & \\
\hline & & & - & $\mathrm{v}, \mathrm{l}$ & $r q, r$ & ri & $r 0, r$ & $\%$ & & 9 \\
\hline 1. & & & - & . & $r$ & ir & tr & 5 & - & \\
\hline 1 & , & , & - & - & $\xi, \Lambda$ & $r 1$ & $7 \xi, r$ & $\%$ & 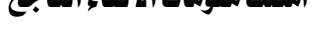 & \\
\hline & & & - & $r$ & 9 & ir & 19 & ك & شخصية الملدرب باستخدام & \\
\hline$\varepsilon$ & $\cdot 979$ & $\xi, 1\}$ & - & $\xi, \Lambda$ & $\mathrm{Y}, \mathcal{\varepsilon}$ & 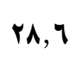 & $\S 0, r$ & $\%$ & اليوتيوبا لها دور اساسي في & $\wedge$ \\
\hline
\end{tabular}

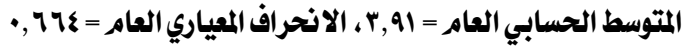


من الجدول (1) يتضـح لنـا أن عبارات الكفايـات الخاصـة بالمدربـة لدى أفراد العينـة

$$
\text { تترتب وفق الترتيب التالي: }
$$

ا - امتلك مقومات الالقاء الناجح حيث بلغ المتوسط الحسابي ( • ج,ء؛) مما يدل على أن أفراد العينة موافقين وبشدة على ذلك.

r- لاي مهارة التعامل مـ الحاسب الالي حيث بلغ المتوسط الحسابي (9, ؟ ) مما يدل على أن أفراد العينة موافقين وبشدة على ذلك.

ب- أستطيع شرح المفاهيم المعقدة بطريقة سهلة حيث بلغ المتوسط الحسابي (T ب, §) مما يدل على أن أفراد العينة موافقين وبشدة على ذلك.

ع - شخصية المدرب باستخدام اليوتيوب لها دور أساسي في نجاح التدريب حيث بلغ المتوسط الحسابي (§ ا, §) مما يدل على أن أفراد العينة موافقين على ذلك. ه- لدي القدرة على تحفيز المتدربين حتى لو لم أكن معهم بشكل مباشر حيث بلغ المتوسط الحسابي (r,90) مما يدل على أن أفراد العينة موافقين على ذلك.

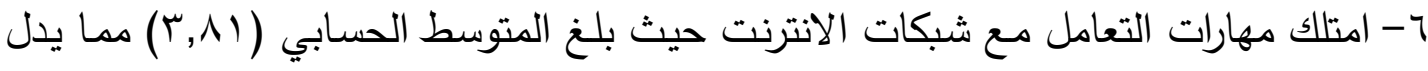
على أن أفراد العينة موافقين على ذلك. V- لدي مهارة تصميم الحقائب التدريبية الاككترونية حيث بلغ المتوسط الحسابي (اY,r) مما يدل على أن أفراد العينة محايدين على ذلك.

^- لدي القدرة على التعامل مع ملفات الفيديو (المونتاج) حيث بلغ المتوسط الحسابي (v •,r) مما يدل على أن أفراد العينة محايدين على ذلك. ويتضـح مـن المتوسـط الحسـابي العـام والبـالغ (1,9) أن أفراد العينـة مـوافقين على

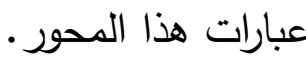
كمـا يتضــح امـتلاك المـدربات لمهـارات التـدريب الأساسـية مـن خــلال الإجابـة

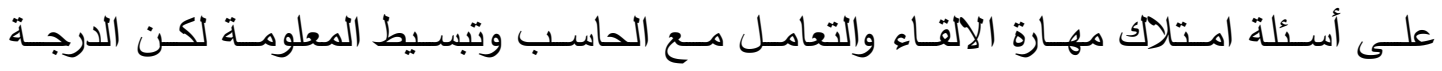
تضــف كلمـا زاد تركيـز السـؤال علـى التـدريب بـاليوتيوب وهـــا نـاتج مـن عـدم أهميــة الموضوع لدى الإدارة. 
ثانياً: معايير تصميم مقاطع اليوتيوب

جلدول (r I ) يبين رأي أفراد العينة حول معايير تصميم مقاطع اليوتيوب

\begin{tabular}{|c|c|c|c|c|c|c|c|c|c|c|}
\hline \multirow[b]{2}{*}{ الترتيب } & \multirow{2}{*}{ الانحراف } & \multirow[b]{2}{*}{ المتوسط } & \multicolumn{5}{|c|}{ درجة المواقة } & \multirow{2}{*}{\multicolumn{2}{|c|}{ العبـــــــــارة }} & \multirow[b]{2}{*}{ هـ } \\
\hline & & & غير موافق & مواقي & 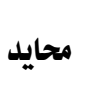 & مواقق & بوافق بـدة & & & \\
\hline \multirow{2}{*}{1} & \multirow{2}{*}{$\cdot, 7 r$} & \multirow{2}{*}{$\varepsilon$, or } & - & - & $r$ & ir & rv & st & يــرتبط المحتــوى بالهـــف المـراد & 9 \\
\hline & & & - & - & $v, 1$ & rA, 7 & רร, r & $\%$ & تحقيقه & \\
\hline \multirow{2}{*}{7} & \multirow{2}{*}{-, 9Ar } & \multirow{2}{*}{$\xi, r \xi$} & - & $r$ & $\checkmark$ & 9 & rr & 5 & \multirow{2}{*}{ سهولة استخدام روابط اليوتيوب } & \multirow{2}{*}{1.} \\
\hline & & & - & $\mathrm{v}, \mathrm{l}$ & $17, r$ & YI, & $\Delta \varepsilon, \Lambda$ & $\%$ & & \\
\hline \multirow{2}{*}{0} & \multirow{2}{*}{$\cdot$, rrr } & \multirow{2}{*}{$\xi, \S 0$} & $\cdot$ & 1 & $\varepsilon$ & ir & ro & 5 & \multirow{2}{*}{ يناسب المقطــع مسـتوى المتـلدربين } & \multirow{2}{*}{11} \\
\hline & & & - & $r, \xi$ & 9,0 & rA, 7 & $\Delta 9,0$ & $\%$ & & \\
\hline \multirow{2}{*}{$\varepsilon$} & \multirow{2}{*}{ •, rrr } & \multirow{2}{*}{$\xi, 0$. } & - & 1 & $\varepsilon$ & 1. & rr & 5 & \multirow{2}{*}{ يناسب وقت المقطع المادة العلميـة } & \multirow{2}{*}{ Ir } \\
\hline & & & - & r,\& & 9,0 & $\mathrm{rr}, \Lambda$ & $7 \varepsilon, r$ & $\%$ & & \\
\hline \multirow{2}{*}{$r$} & \multirow{2}{*}{$\cdot, \mathrm{Y} \xi \cdot$} & \multirow{2}{*}{$\boldsymbol{\xi}$, or } & - & 1 & $r$ & 11 & rV & 5 & \multirow{2}{*}{ يصــف عنـــوان المقطـــع المحتــوى } & \multirow{2}{*}{ ir } \\
\hline & & & • & r, & $v, 1$ & $r q, r$ & $7 \xi, r$ & $\%$ & & \\
\hline \multirow{2}{*}{$r$} & \multirow{2}{*}{$\cdot, r \cdot v$} & \multirow{2}{*}{$\boldsymbol{\xi}$, Or } & - & 1 & $r$ & ir & rq & 5 & \multirow{2}{*}{ تقتـليــ تفذيــة راجعـة مسن خـلال } & \multirow{2}{*}{18} \\
\hline & & & . & $r, \xi$ & $\boldsymbol{\xi}, \Lambda$ & H & 71,9 & $\%$ & & \\
\hline
\end{tabular}

من الجدول (Y Y ( ) يتضـح لنـا أن عبارات معايير تصميم مقاطع اليوتيوب لدى أفراد

$$
\text { العينة تترتب وفق الترتيب التالي: }
$$

ا - يرتبط المحتوى بالهدف المراد تحقيقه حيث بلغ المتوسط الحسابي (I,OV ) مما يدل على أن أفراد العينة موافقين وششدة على ذلك.

r- تقديم تغذية راجعة من خلال وجود ايقونة للردود على المقاطع حيث بلغ المتوسط الحسابي ( ), مما يدل على أن أفراد العينة موافقين وبشدة على ذلك. ب- يصف عنوان المقطع المحتوى المقدم حيث بلغ المتوسط الحسابي (r,O, ) مما يدل على أن أفراد العينة موافقين وبشدة على ذلك.

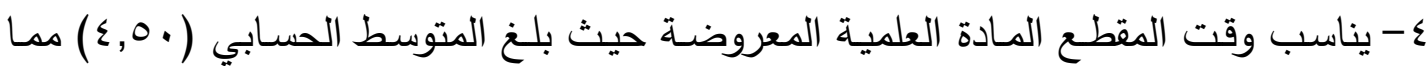
يدل على أن أفراد العينة موافقين وبشدة على ذلك. 0- يناسب المقطع مستوى المتدربين العلمي حيث بلغ المتوسط الحسابي (0 ـ, ؟) مما يدل على أن أفراد العينة موافقين وبشدة على ذلك. ד- سهولة استخدام روابط اليوتيوب حيث بلغ المتوسط الحسابي (ع ז, §) مما يدل على أن أفراد العينة موافقين وبشدة على ذلك. 
ويتضح من المتوسط الحسابي العام والبالغ (7؟ ــ) أن أفراد العينة موافقين وبشدة على

عبارات هذا المحور • وهذا يدل على استعداد المدربات لتفعيل التدريب الالكتروني واقتتاعهر بفوائده ومعرفته بمقومات نجاحه ولا تتفق هذه النتيجة مع دراسة فروانة (Y ( ا ب)، حيث يعتبر عملية تحميل مقاطع الفيديو من اليوتيوب عملية صعبة لأنها تتم عبر برمجيات خاصسة بينما

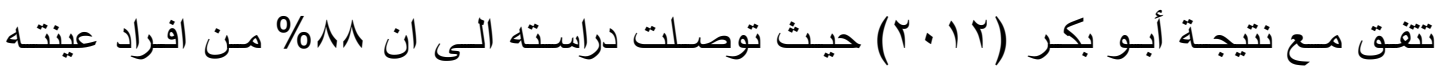
يستعملون قنوات اليوتيوب.

ثالثاً: جودة برامج التدريب بمقاطع اليوتيوب

جلول ( آ ) يبين رأي أفراد المينة حول جودة برامج التدريب بمقاطع اليوتيوب

\begin{tabular}{|c|c|c|c|c|c|c|c|c|c|c|}
\hline \multirow[b]{2}{*}{ الترتيب } & \multirow{2}{*}{ الالخحراف } & \multirow[b]{2}{*}{ المتوسط } & \multicolumn{5}{|c|}{ درجة المواقتة } & \multirow{2}{*}{\multicolumn{2}{|c|}{ العبـــــــــــــــارة }} & \multirow[b]{2}{*}{ مـ D D } \\
\hline & & & غير موافق & غمبر & محايل & مواقق & بشلة & & & \\
\hline \multirow[b]{2}{*}{1} & \multirow[b]{2}{*}{ •, Yrq } & \multirow[b]{2}{*}{$\xi, Y)$} & - & 1 & 1 & $v$ & rr & كt & \multirow{2}{*}{ الاولقاء عامل مهم عند الصوت اثناء } & \\
\hline & & & • & 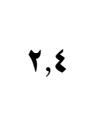 & $\boldsymbol{Y}, \boldsymbol{\xi}$ & $17, V$ & VA, 7 & $\%$ & & 10 \\
\hline \multirow{2}{*}{$r$} & \multirow{2}{*}{$\cdot, 770$} & \multirow{2}{*}{$\xi\rceil}$. & - & 1 & 1 & ir & ra & st & \multirow{2}{*}{ يهمني جودة الإخراج } & \multirow{2}{*}{17} \\
\hline & & & - & r,§ & r,そ & rA, 7 & $77, Y$ & $\%$ & & \\
\hline \multirow{2}{*}{$r$} & \multirow{2}{*}{$\cdot, 7 \cdot 8$} & \multirow{2}{*}{$\varepsilon, 79$} & - & - & $r$ & $\checkmark$ & rr & st & \multirow{2}{*}{ أتأكد من سلامة المقطع } & \multirow{2}{*}{ IV } \\
\hline & & & • & - & $v, 1$ & $17, v$ & $v \eta, r$ & $\%$ & & \\
\hline
\end{tabular}

من الجدول (r ( ) يتضـح لنا أن عبارات جودة برامج التدريب بمقاطع اليوتيوب لدى

$$
\text { أفراد العينة تترتب وفق الترتيب التالي. }
$$

1-وضوح الصوت اثناء الالقاء عامل مهم عند تصميم المقاطع حيث بلغ المتوسط الحسابي

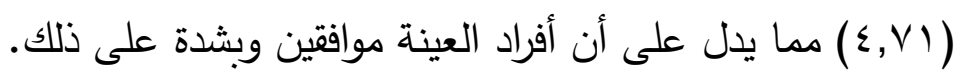
ץ- أتأكد من سلامة المقطع من الفيروسات حيث بلغ المتوسط الحسابي (99, ؟) مما يدل على أن أفراد العينة موافقين وبشدة على ذلك. ب- يهمني جودة الإخراج الفني للمقاطع حيث بلغ المتوسط الحسابي ( • ؟, ع) مما يدل على أن أفراد العينة موافقين وبشدة على ذلك. 
ويتضح من المتوسط الحسابي العام والبالغ (ד 7,؟) أن أفراد العينة موافقين وبشدة على عبارات هذا المحور ، وتعطي الإجابات انطباعا عامـا عن أكثر مـا يهم المدربات وهو سـلامة الصوت في المقطع وهو تفكير منطقي لان الصوت هو اول محرك للمتدرب الذي لا يكون امام المدرب. كما ان سلامة المقطع من الفيروسات امر بالغ الأهمية لدى المدربات وكذلك الإخراج فهو عامل جذب لا يمكن إهماله عند اعداد فديو تعليمي. ويتضح اتفاق افراد العينة حول هذا المحور ومعرفة مدربات ادارة التدريب بمعايير جودة التدريب باليوتيوب بالرغم من عدم ممارسة أغلبهن لهذا النوع من التدريب رابـعاً: تقبيبم برامج التندربب بـمقاطع اليوتبوب

جلدول (§) يبين رأي أفراد العينة حول تقييم برامج التدريب بمقاطع اليوتيوب

\begin{tabular}{|c|c|c|c|c|c|c|c|c|c|c|}
\hline \multirow[b]{2}{*}{ التزتيب } & \multirow{2}{*}{ الانحراف } & \multirow[b]{2}{*}{ المتوسط } & \multicolumn{5}{|c|}{ درجة المواقتة } & \multirow{2}{*}{\multicolumn{2}{|c|}{ العبارة }} & \multirow[b]{2}{*}{ مر } \\
\hline & & & غير موافق & غواقق & محايل & موافق & موافق & & & \\
\hline \multirow[b]{2}{*}{$\xi$} & \multirow[b]{2}{*}{$\cdot 919$} & \multirow[b]{2}{*}{$r, Y \varepsilon$} & - & $\varepsilon$ & 10 & 11 & ir & st & \multirow{2}{*}{ من يمكنني هذا النوع من التدريب أثبر التدريب بطريقه } & \multirow[b]{2}{*}{11} \\
\hline & & & • & 9,0 & $r o, r$ & $r q, r$ & rA, $\urcorner$ & $\%$ & & \\
\hline \multirow[b]{2}{*}{$r$} & \multirow[b]{2}{*}{ •, マYร } & \multirow[b]{2}{*}{$\boldsymbol{\xi}, \bullet$} & - & 1 & $\Lambda$ & $M$ & ir & 5 & \multirow{2}{*}{ 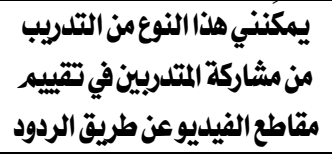 } & \multirow[b]{2}{*}{19} \\
\hline & & & • & r,そ & 19 & 0. & $r \wedge, \eta$ & $\%$ & & \\
\hline \multirow{2}{*}{1} & \multirow{2}{*}{ •, YOs } & \multirow{2}{*}{ \&, rr } & . & 1 & $\xi$ & iv & $r$. & S & \multirow{2}{*}{ سلامة المقاطع لفويا أنتاكلد بنفي من } & \multirow{2}{*}{$r_{\varphi}$} \\
\hline & & & . & $r, \xi$ & 9,0 & $\xi \bullet, 0$ & $\xi \vee, \eta$ & $\%$ & & \\
\hline \multirow{2}{*}{$r$} & \multirow{2}{*}{ - Aro } & \multirow{2}{*}{$r, 90$} & . & 1 & $\pi$ & iv & ir & 5 & \multirow{2}{*}{ أستطيع تحديل موثوقية } & \multirow{2}{*}{$M$} \\
\hline & & & - & $r, \xi$ & YA, Y & $\xi \cdot, 0$ & $r \wedge, Y$ & $\%$ & & \\
\hline \multirow{2}{*}{0} & \multirow{2}{*}{$1, \cdot v$} & \multirow{2}{*}{$r, 7 q$} & • & $\Lambda$ & $\Lambda$ & 10 & 11 & st & \multirow{2}{*}{ يناسب جمميع فئات المجتمع التيبو } & \multirow{2}{*}{$\begin{array}{l}r \\
r\end{array}$} \\
\hline & & & • & 19 & 19 & $r o, r$ & $r \eta, r$ & $\%$ & & \\
\hline & & & $r \Lambda=A$ & المعيار & الاذ & $=0$ & جسابي & 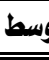 & & \\
\hline
\end{tabular}

من الجدول (ع () يتضح لنا أن عبارات تقييم برامج التدريب بمقاطع اليوتيوب لدى أفراد

$$
\text { العينة تترتب وفق الترتيب التالي: }
$$

ا- أستطيع ان أتأكد بنفسي مـن سـلامة المقاطع لغويـا وعلميا حيث بلـن المتوسط الحسـابي

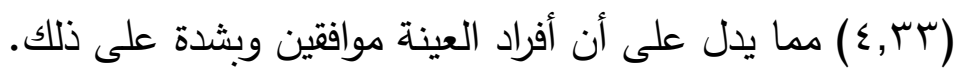
r- يمكًني هذا النوع من التدربب من مشاركة المتدربين في تقييم مقاطع الفيديو عن طريق الردود حيث بلغ المتوسط الحسابي (0. , ع) مما يدل على أن أفراد العينة موافقين على ذلك. 
ب- أستطيع تحديد موثوقية مصدر الفيديو حيث بلغ المتوسط الحسابي (1,90) مما يدل على أن أفراد العينة موافقين على ذلك. ع- يمكًني هذا النوع من التدريب من قياس أثر التدريب بطريقه أكبر عن طريق التكليفات التي

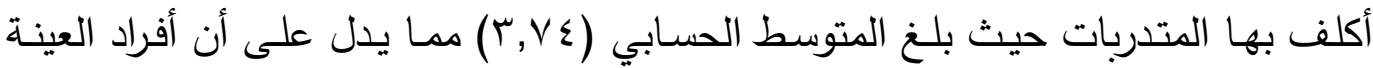
موافقين على ذلك. ه- اسـتخدام التـدريب بـاليوتيوب يناسـب جميع فئـات المجتمـع حيـث بــن المتوسـط الحسـابي

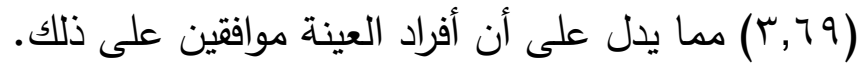

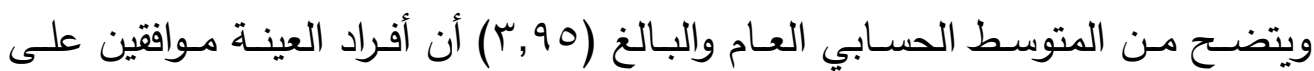
عبارات هذا المحور .

يتضح من إجابات المدربات ثقتهن في مؤهلاتهن العلمية واللغويـة كما اقرت المدربات بإمكانية تفاعل المتدربات معهن في تقييم المقاطع واستطاعتهن تحديد موثوقية المصدر ، وأقرت المدربات بإمكانية قياس الأثر على المتدربات عن طريق التكليفات. جاءت عبارة أستطيع أن أتأكد بنفسي من سلامة المقاطع لغويا وعلميا بمتوسط حسابي (TM، §) مما يدل على قدرات المدربات اللغويـة والعلميـة بينمـا كانت عبارة استخدام التدريب باليوتيوب يناسب جميع فئات المجتمع بمتوسط (79،ب) وهنا ظهر بعض الاختلاف في رأي المدربات حول مناسبة استخدام التدريب اليوتيوب لجميع فئات المجتمع وربما يعود ذلك الى لى الخبرات المختلفة التي مرت بها المدربة. اختبار تحليل التباين لمعرفة الفروق الإحصائية للمحاور بالنسبة لمتغير الدرجة العلمية: جلول (10) يوضح اختبار (T) لبيان الفروق بين إجابات أفراد العينة بحسب متفير الدرجة العلمية

\begin{tabular}{|c|c|c|c|c|c|c|}
\hline الإحصائية & قيمة & الحرية & الالمياري & الحسابي & العلمية & 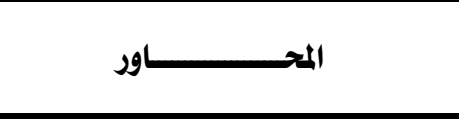 \\
\hline \multirow{2}{*}{$\cdot, r \cdot r$} & \multirow{2}{*}{$\cdot, \Gamma \wedge \varepsilon$} & \multirow{2}{*}{$\xi$} & $\cdot, \mathrm{nII}$ & $r, 90$ & بكالوريوس & \multirow{2}{*}{ الكفايات الخاصة بالمدربة } \\
\hline & & & • Trr & $r, \wedge \mathrm{r}$ & ماجستير & \\
\hline \multirow{2}{*}{$\bullet, \bullet \wedge 7$} & \multirow{2}{*}{$1, \vee 4$} & \multirow{2}{*}{ \&. } & $\cdot, \& \vee q$ & $\xi, \boldsymbol{T}$ & 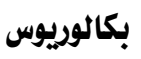 & \multirow{2}{*}{ معايير تصميم مقاطع اليوتيوب } \\
\hline & & & $\cdot, \mathrm{V} \S 0$ & $\xi, r q$ & ماجستير & \\
\hline \multirow{2}{*}{$* \bullet, \cdot \bullet r$} & \multirow{2}{*}{ r,Yq4 } & \multirow{2}{*}{$\xi$} & $\cdot, 119$ & $\varepsilon, \wedge 9$ & بكالوريوس & \multirow{2}{*}{ جودة برامج التدريب بمقاطع اليوتيوب } \\
\hline & & & $\cdot, 707$ & $\xi, \xi 1$ & ماجستير & \\
\hline \multirow{2}{*}{$\cdot, 1 \cdot r$} & \multirow{2}{*}{1,771} & \multirow{2}{*}{$\xi$} & •, & $\xi, \bullet \wedge$ & بكالوريوس & \multirow{2}{*}{ تقييم برامج التدريب بمقاطع اليوتيوب } \\
\hline & & & • & $r, \wedge l$ & ماجستير & \\
\hline
\end{tabular}




$$
\text { يتبين من الجدول رقم (10 ) ما يلي: }
$$

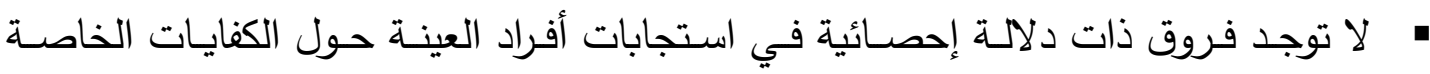

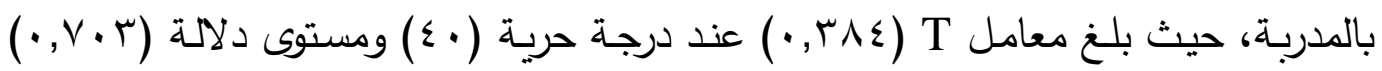

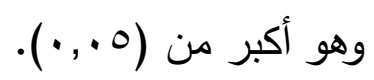

لا توجد فروق ذات دلالة إحصائية في استجابات أفراد العينة حول معايير تصميم مقاطع

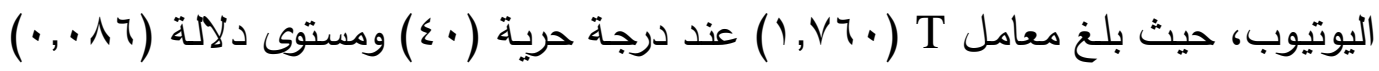

$$
\text { وهو أكبر من (0., •) ). }
$$

توجد فروق ذات دلالـة إحصـائية في استجابات أفراد العينـة حول جودة بـرامج التدريب

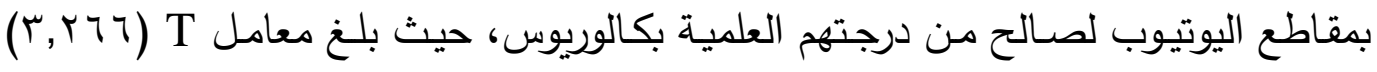

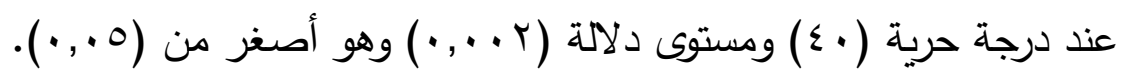

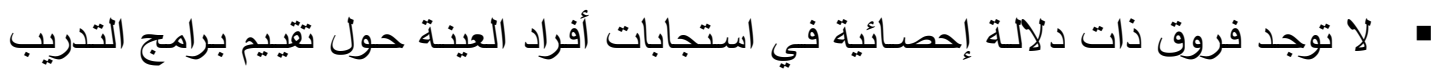

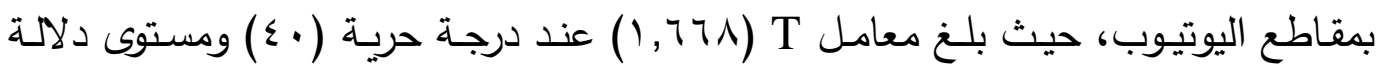

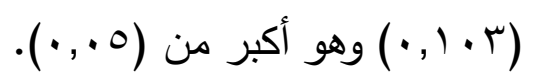

\begin{tabular}{|c|c|c|c|c|c|c|}
\hline مستوى اللالة & قيمة & متوبعات & دالحرية & مجمجوع & مصلر التباين & ور \\
\hline \multirow{2}{*}{ •, $Y 19$} & \multirow{2}{*}{ errr } & •, 101 & $r$ & 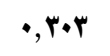 & بين المجموعات & \multirow{2}{*}{ الكفايات الخاصة بالمدربة } \\
\hline & & 年, \$07 & $r q$ & $|Y, Y A|$ & داخل المجموعات & \\
\hline \multirow{2}{*}{ •, qri } & \multirow{2}{*}{$\bullet$} & 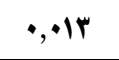 & $r$ & •., ro & بيز المجموعات & \multirow{2}{*}{ معايير تصمير مقاطع اليوتيوب } \\
\hline & & 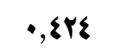 & rq & $17,0 \leqslant \xi$ & داخل المجموعات & \\
\hline \multirow{2}{*}{ • 147} & \multirow{2}{*}{ 1, vor } & 年, & $r$ & •, & بين المجموعات & \multirow{2}{*}{ جودة برامج التدريب بمقاطع اليوتيوب } \\
\hline & & $\cdot, r q r$ & rq & 1., rav & داخل المجموعات & \\
\hline \multirow{2}{*}{ 年, } & \multirow{2}{*}{$\bullet, A \cdot 7$} & דוזים & $r$ & 㑊, \&VT & بين المجموعات & \multirow{2}{*}{ تقيييم برامج التدريب بمقاطع اليوتيوب } \\
\hline & & 要, rar & ra & $11, \varepsilon \mathrm{Er}$ & داخل المجموعات & \\
\hline
\end{tabular}

• اختبار تحليل التباين لمعرفة الفروق الإحصائية للمحاور بالنسبة لمتغير عدد سنوات الخبرة:

\section{جلدول (17) يوضح اختبار تحليل التباين لبيان الفروق الإحصائية}

بين إجابات أفراد العينة بحسب متفير علد سنوات الخبرة الخبرة

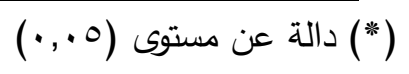




$$
\text { يتبين من الجدول رقم (7 1 ) ما يلي: }
$$

• لا توجد فروق ذات دلالــة إحصـائية في استجابات أفراد العينـة حـل الكفايـات الخاصــة

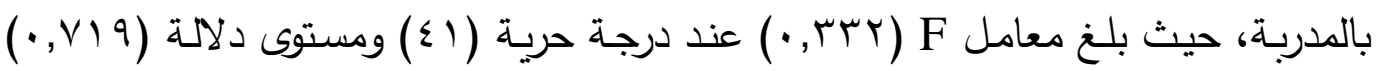

$$
\text { وهو أكبر من (0. +. •). }
$$

• لا توجد فروق ذات دلالة إحصائية في استجابات أفراد العينة حول معايير تصميم مقاطع

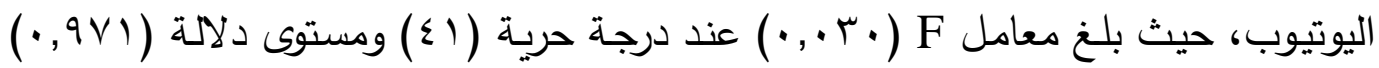

$$
\text { وهو أكبر من (0. . •).). }
$$

• لا توجد فروق ذات دلالتة إحصائية في استجابات أفراد العينـة حول جودة برامج التدريب

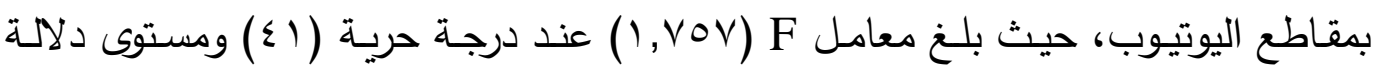

$$
\text { (0., (1)7) }
$$

• لا توجد فروق ذات دلالـة إحصـائية في استجابات أفراد العينـة حول تقييم برامج التدريب

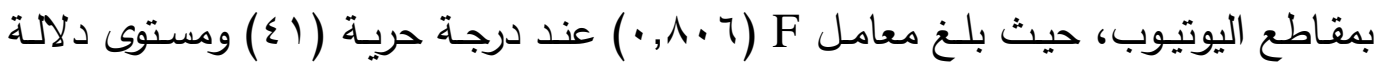

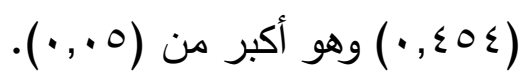

\begin{tabular}{|c|c|c|c|c|c|c|}
\hline الدلالة & قيمة & متروسط & درجات & مجمبوع & مصلدر التباين & 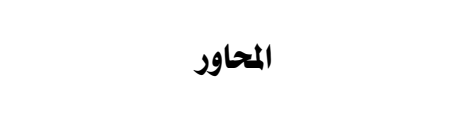 \\
\hline \multirow{2}{*}{$* \bullet, \cdots 1$} & \multirow{2}{*}{0, \&OY } & $1,9 \vee 7$ & $r$ & $r, 901$ & بين المجموعات & \multirow{2}{*}{ الكفايات الخاصة بالمدربة } \\
\hline & & $\cdot$, rmr & rq & $1 \xi, I T r$ & داخل المجموعات & \\
\hline \multirow{2}{*}{$\cdot, 141$} & \multirow{2}{*}{$1, Y \leqslant 0$} & $\cdot 711$ & $r$ & $1,+41$ & بين المجموعات & \multirow{2}{*}{ معايير تصمير مقاطع اليوتيوب } \\
\hline & & . rq. & rq & $10, r \cdot 1$ & داخل المجموعات & \\
\hline \multirow{2}{*}{$\cdot, 0 \cdot 1$} & \multirow{2}{*}{$\cdot, 79}$. & $\cdot, 19 \xi$ & r & • rar & بين المجموعات & \multirow{2}{*}{ جودة برامج التدريب بمقاطع اليوتيوب } \\
\hline & & $\cdot, r \Lambda 1$ & rq & 1.,9ะ7 & داخل المجموعات & \\
\hline \multirow{2}{*}{$* \bullet, \cdots 1$} & \multirow{2}{*}{0, OrY } & $1, r \mid \xi$ & $r$ & $r, T r Y$ & بين المجموعات & \multirow{2}{*}{ تقييم برامج التدريب بمقاطع اليوتيوب } \\
\hline & & , rrA & rq & $9, r Y r$ & داخل المجموعات & \\
\hline
\end{tabular}

• اختبار تحليل التباين لمعرفة الفروق الإحصائية للمحاور بالنسبة لمتغير عدد الدورات في

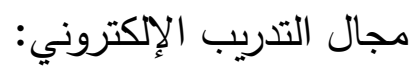

جلول (IV) يوضح اختبار تحليل التباين لبيان الفروق الإحصائية

بين إجابات أفراد العينة بحسب متفير عدد اللدورات في مجال التدريب الإلكتروني

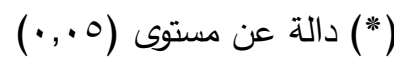




\section{يتبين من الجدول رقم (IV) ما يلي:}

توجد فروق ذات دلالـة إحصـائية في استجابات أفراد العينـة حول الكفايـات الخاصـة

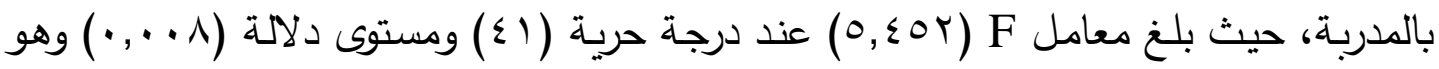

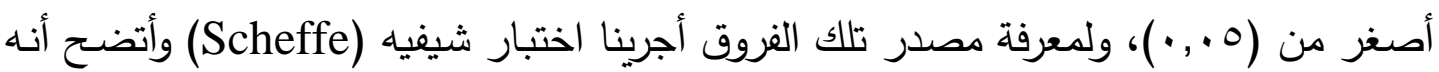
توجد فروق ذات دلالة إحصائية بين من عدد دوراتهم من ا - ب دورات ومن عدد دوراتهم أكثر

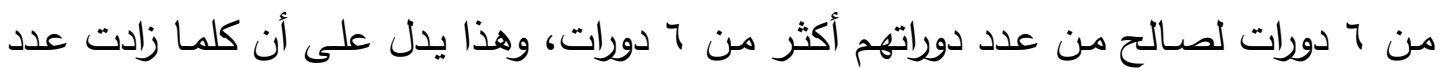
الدورات زادت الكفايات الخاصة بالمدربة

جدول (11) يبين مصدر الفروق لاختبارشيفيه (Scheffe)

\begin{tabular}{|c|c|c|c|c|}
\hline \multicolumn{3}{|c|}{ علد الدوراتو متوسطاتها } & & \\
\hline أكثر من 7 & $7-\xi$ & $r-1$ & & \\
\hline$\xi$, YO & $\boldsymbol{r}, \Delta \boldsymbol{\mu}$ & $r, 7 r$ & & \\
\hline & & & $r-1$ & \multirow{6}{*}{ علد اللوررات ومتوسطاتها } \\
\hline & & & $r, 7 r$ & \\
\hline & & - , $7 \leqslant 0$ & $7-\varepsilon$ & \\
\hline & & & $\boldsymbol{T}, \boldsymbol{\Lambda} T$ & \\
\hline & \multirow{2}{*}{$\cdot, 1 \cdot r$} & \multirow{2}{*}{$* \bullet, \cdot \cdot 9$} & أكثر من 7 & \\
\hline & & & ร, Yo & \\
\hline
\end{tabular}

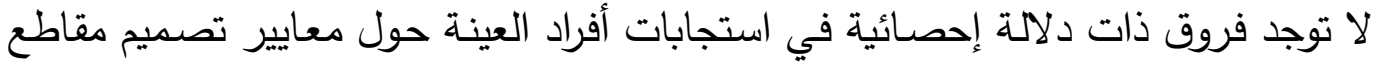

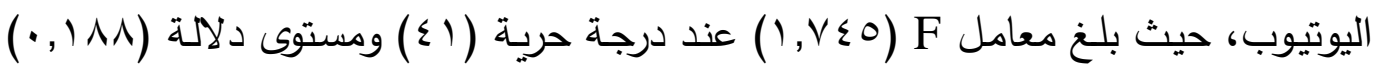

$$
\text { وهو أكبر من (0., · •). }
$$

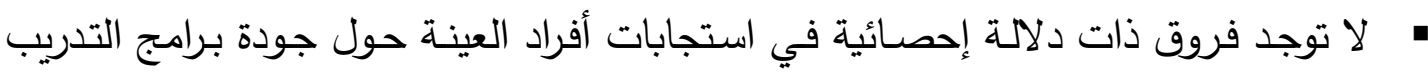

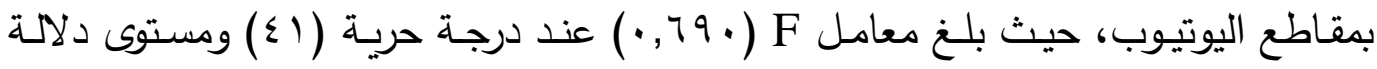

$$
\text { تو }
$$

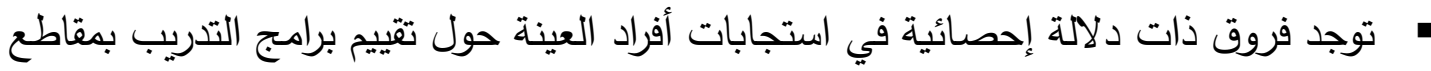

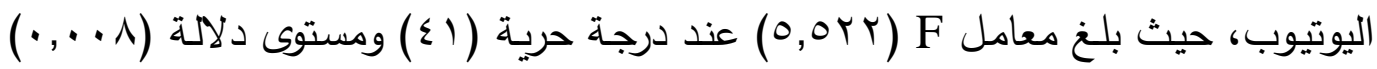
وهو أصغر من (0., .•)، ولمعرفة مصدر تلك الفروق أجرينا اختبار شيفيه (Scheffe)

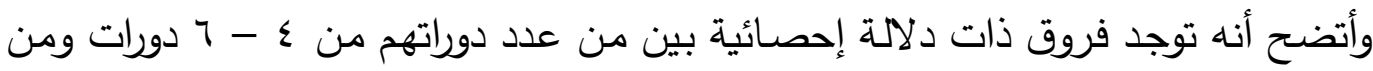


عدد دوراتهم أكثر من 7 دورات لصالح من عدد دوراتهم أكثر من 7 دورات، وهذا يدل على انه كلما زادت عدد الدورات زاد استجابة المدربة لتقييم البرنامج. جدول (19) يبين مصلدر الفروق لاختبارشيفيه (Scheffe)

\begin{tabular}{|c|c|c|c|c|}
\hline \multicolumn{3}{|c|}{ عدد الدوراتو متوسطاتها } & & \\
\hline أكثر من 7 & $\begin{array}{l}7-\xi \\
r, 77\end{array}$ & $\begin{array}{l}r-1 \\
r, q 1\end{array}$ & & \\
\hline & & & $\begin{array}{l}r-1 \\
r, q 1\end{array}$ & \multirow{3}{*}{ عدد الدورات و متوسطاتها } \\
\hline & & •, r97 & $\begin{array}{l}7-\xi \\
r, 79\end{array}$ & \\
\hline & $* \bullet, \cdots \wedge$ & $\cdot, I r v$ & أكثر من 7 أ & \\
\hline
\end{tabular}

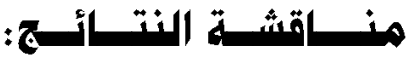

مناقشة النتائج المتعلقة بالمحور الأول الكفايات الخاصة بالمدربة

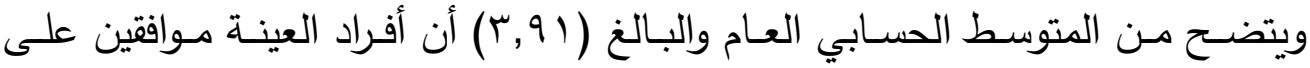

عبارات هذا المحور . كما يتضح امتلاك المدربات لمهارات التدريب الأساسية من خلال الإجابة

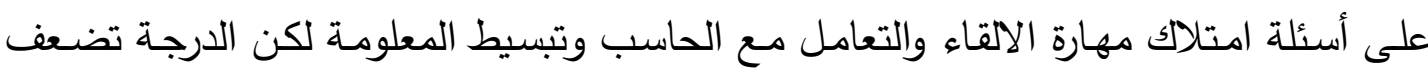

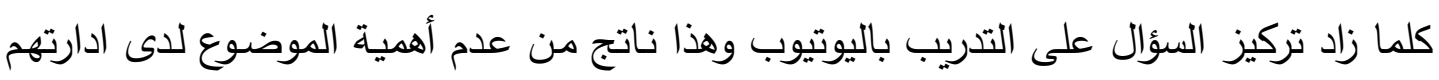

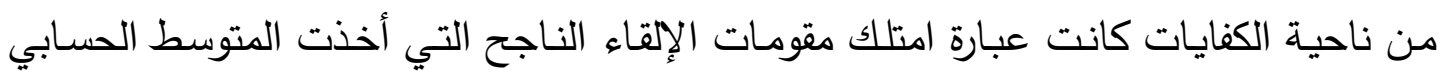

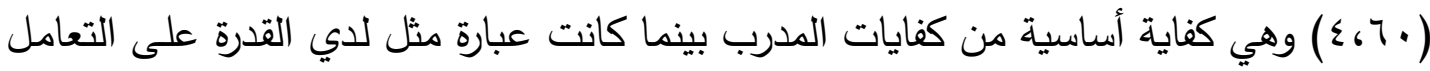

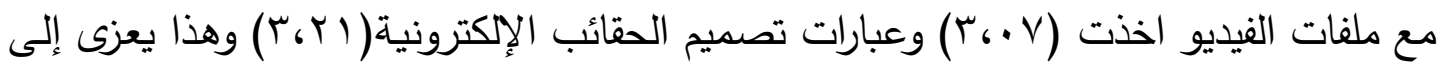
ضعف التدريب الذي تتلقاه المدربة على هذا النوع من التدريب الإلكتروني وهو ناتج من تحفظ

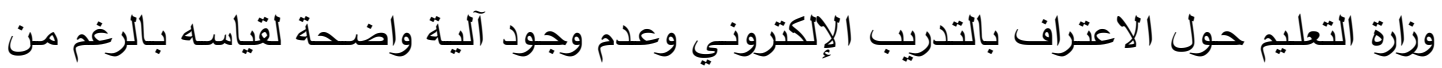

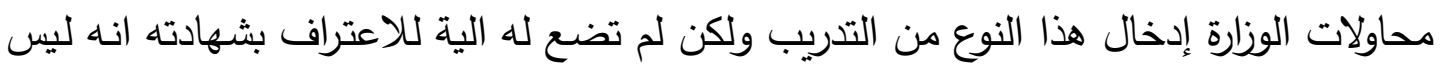

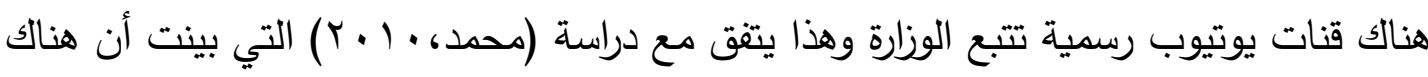
قناتين عربيتين فقط هما مكتبة الإسكندرية في مصر ومكتبة المحمود في الثـارقة من بين

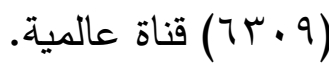




\section{مناقشة نتائج المحور الثاني معايير تصميه مقاطع اليوتيوب}

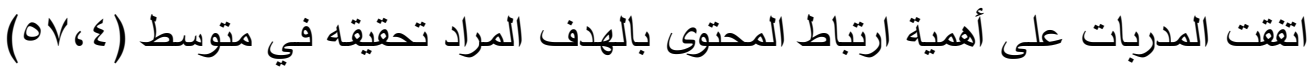

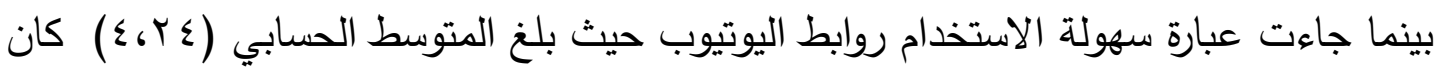
أقل متوسط في هذا المحور وهو متوسط عالي مما يدل على أن افراد العينة لديهم ثثافة كافية

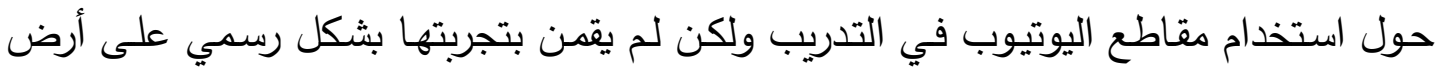
الواقع نظرا لعدم تحمس ادارتهن لهذا النوع من التدريب.

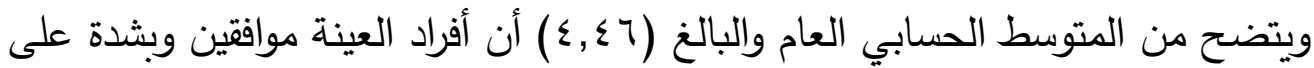
عبارات هذا المحور • وهذا يدل على استعداد المدربات لتفعيل التدريب الالكتروني واقتناعهم

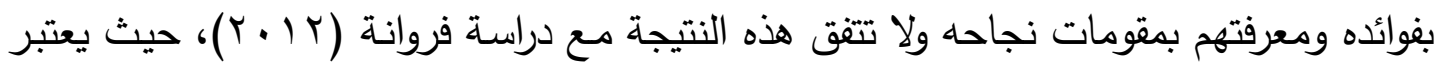

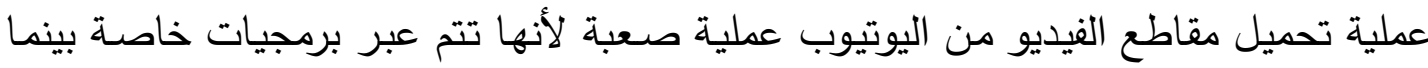

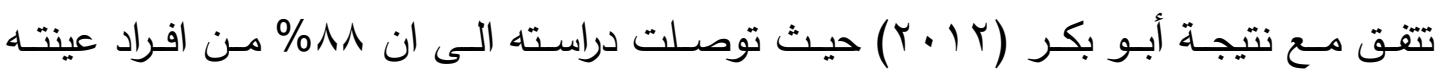

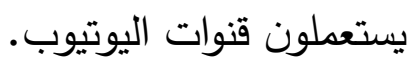

\section{مناقشة نتائج المحور الثالث جودة برامج التدريب بمقاطع اليوتيوب}

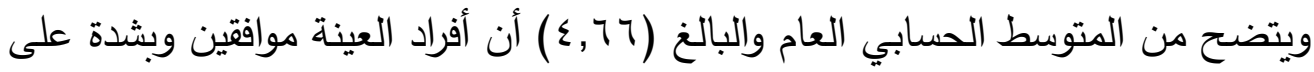
عبارات هذا المحور ، وتعطي الإجابات انطباعا عاما عن أكثر ما يهم المدربات وهو سلامة

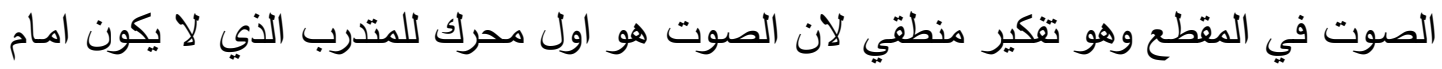
المدرب. كما ان سلامة المقطع من الفيروسات امر بالغ الأهمية لدى المدربات وكذلك الكي الإخراج فهو عامل جذب لا يمكن إهماله عند اعداد فديو تعليمي. ويتضح اتفاق افراد العينة حول هذا المحور ومعرفة مدربات ادارة التدريب بمعايير جودة التدريب باليوتيوب بالرغم من عدم ممارسة أغلبهن لهذا النوع من التدريب وهي تتفق مع نتائج

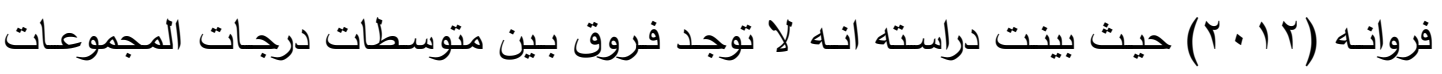
التجريبية والضـابطة في الاختبار المعرفي وهنا السؤال للمدربات لا يتعدى المعرفة وليس لدينا تجربه عملية لمعرفة مستوى المدربات المهاري.

\section{مناقشة المحور الرابع تقييم برامج التدريب بمقاطع اليوتيوب}

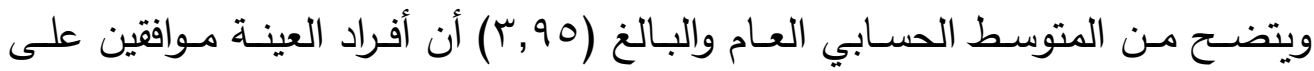

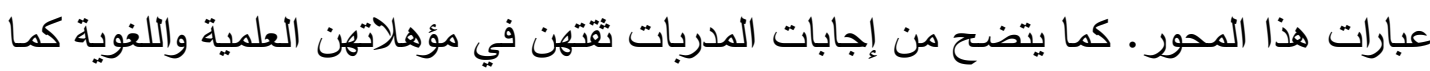


اكدت المدربات على امكانيـة تقاعل المتدربات معهن في تقييم المقاطع واستطاعتهن تحديد موثوقية المصدر ، وأقرت المدربات بإمكانية قياس الأثر على المتدربات عن طريق التكليفات وهي تتفق بذلك مع دراسة Carlisle(2010 في ان اليوتيوب يساهم في زيادة نسبة التدريب العملي والتأثير المباشر على المستوى التحصيلي للمتدرب وظهر بعض الاختلاف في رأي المدربات حول مناسبة استخدام التدريب باليوتيوب لجميع فئات المجتمع وربما يعود ذلك الى الخبرات المختلفة التي مرت بها المدربة.

ا- ضرورة اعتراف وزارة التعليم بالتدريب الالكتروني بمنح شهادات معترف بها من قبلها. ץ- إقامـة دورات تدريبية مكثفة لمنسـوبات إدارة التدريب على التدريب عن بعد عمومـا والتدريب باستخدام اليوتيوب خصوصا.

ب- نشـر ثقافـة التـدريب باسـتخدام اليوتيـوب بـين منسـوبات وزارة التعليم مسن مـدربات

$$
\text { ومشرفات ومعلمات وطالبات. }
$$

$$
\text { ع- تجهيز مراكز التدريب بأنظمة التدريب الاككتروني. }
$$

0- توفير قاعات مجهزه للمدربات لإعداد انتاجهم التعليمي المعتمد على قنوات اليوتيوب. ج- توفير كوادر مدربـة للدعم الفني التابع لإدارات التدريب يدعم المدربات في العمليات الفنية الخاصة بالإنتاج الفني لمقاطع الفيديو باليوتيوب. V - Vشاء قنوات متخصصة بالتدريب تتبع وزارة التعليم وتحت مظلتها. 


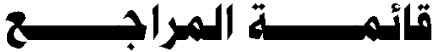

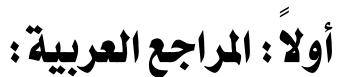

باقر ، عماد. (ع ( • Y). أساليب جديدة في التدريب يقدمها التدريب الإكتروني. تم استرجاعه

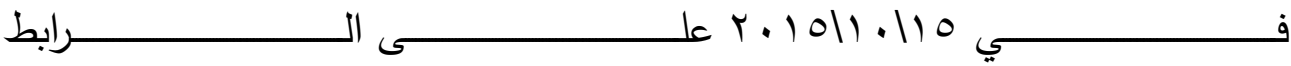

.http://www.atheer.om/Article/Index/6519\#

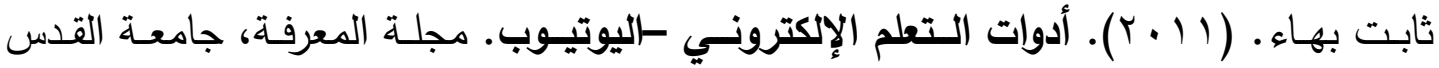

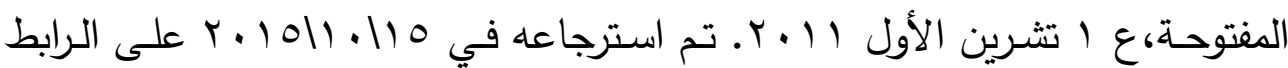

.http://www.qou.edu/newsletter/no_1/youTube.jsp

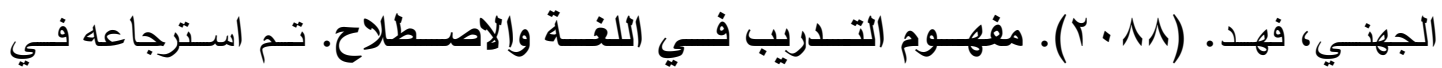
رابط ال L.r.1011.11

http://www.arbi.ws/vb/showthread.php?p=27083 حجازي، وجدي.(· ( • (ب). التدريب في القرن الحادي والعشرين. القاهرة: دار التعليم الجامعي.

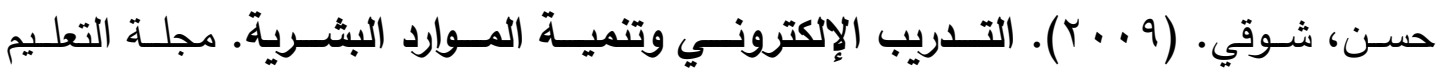

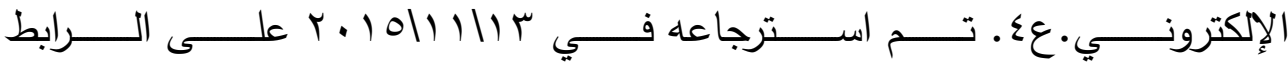
http://emag.mans.edu.eg/index.php?sessionID=13\&page=news\& .task $=$ show \&id $=140$

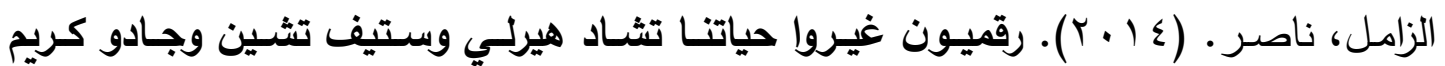
وتأسيس موقع اليوتيوب. الرياض: العبيكان.

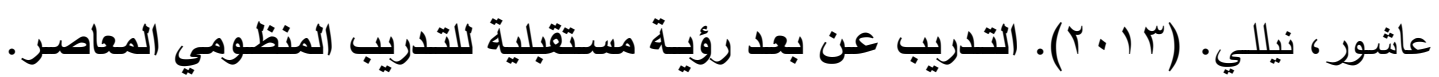

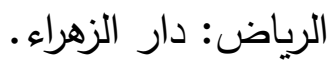

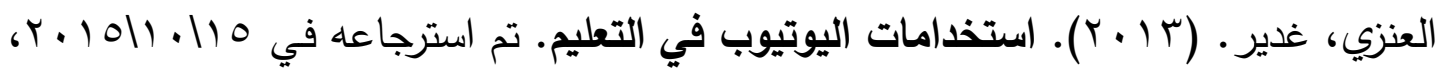

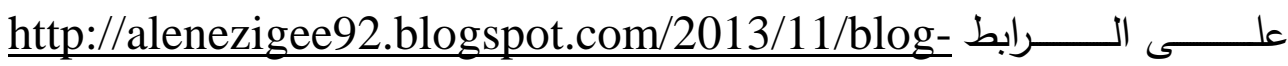
post.html

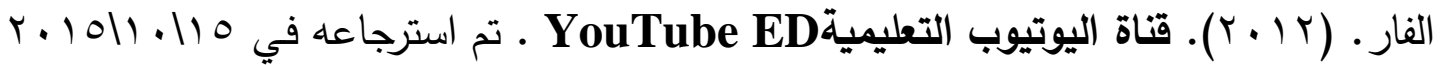
رابط l) e

http://youtubeandedu.blogspot.com/2012/12/youtube-

edu.html 
فراونة، اكرم. (Y ( • Y). فاعلية استخدام مواقع الفيديو الإلكترونية في اكتساب مهارات تصميم

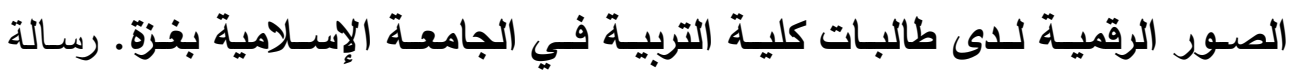

ماجستير غير منشورة، الجامعة الإسلامية غزة، فلسطين.

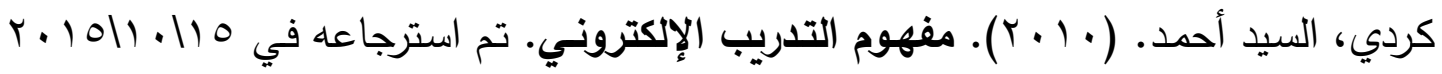

http://kenanaonline.com/users/ahmedkordy/posts/153528 على الرابط

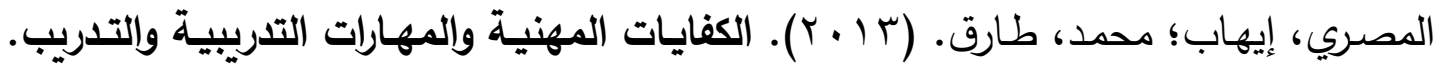

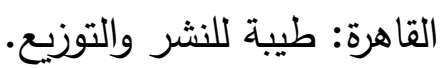

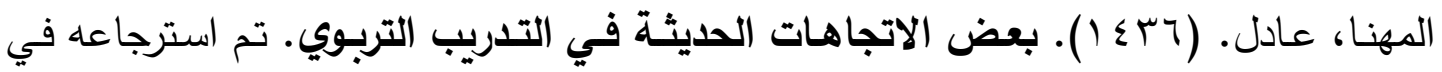

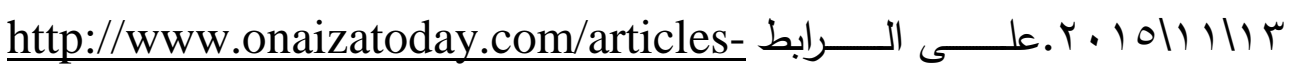
action-show-id-658.htm

ثانياً : المراجع الأجنبية :

Findley, H., Reynolds, A., Davis, B., \& Belcher, W. (2013). Evolution of and current trends in training. Troy University. http://www.aabri.com/NO2013Manuscripts/NO13056.pdf . 